Article

\title{
Intersystem Bias in GPS, GLONASS, Galileo, BDS-3, and BDS-2 Integrated SPP: Characteristics and Performance Enhancement as a Priori Constraints
}

\author{
Lin Pan ${ }^{1,2,3}$, Zhehao Zhang ${ }^{1}$, Wenkun Yu ${ }^{1, *(D)}$ and Wujiao Dai ${ }^{1}$ (D) \\ 1 School of Geosciences and Info-Physics, Central South University, Changsha 410083, China; \\ linpan@csu.edu.cn (L.P.); zhangzh@csu.edu.cn (Z.Z.); wjdai@csu.edu.cn (W.D.) \\ 2 State Key Laboratory of Geo-Information Engineering, Xi'an 710054, China \\ 3 Guangxi Key Laboratory of Spatial Information and Geomatics, Guilin 541004, China \\ * Correspondence: geowkyu@csu.edu.cn
}

check for

updates

Citation: Pan, L.; Zhang, Z.; Yu, W.; Dai, W. Intersystem Bias in GPS, GLONASS, Galileo, BDS-3, and BDS-2 Integrated SPP: Characteristics and Performance Enhancement as a Priori Constraints. Remote Sens. 2021, 13, 4650. https://doi.org/10.3390/ rs13224650

Academic Editors: Jay Hyoun Kwon, Chang-Ki Hong and Tae-Suk Bae

Received: 8 October 2021

Accepted: 16 November 2021

Published: 18 November 2021

Publisher's Note: MDPI stays neutral with regard to jurisdictional claims in published maps and institutional affiliations.

Copyright: (c) 2021 by the authors. Licensee MDPI, Basel, Switzerland. This article is an open access article distributed under the terms and conditions of the Creative Commons Attribution (CC BY) license (https:// creativecommons.org/licenses/by/ $4.0 /)$.

\begin{abstract}
Global navigation satellite systems (GNSSs) have been booming in recent years, and the space segment of all four of the GNSSs, including BDS (BDS-3/BDS-2), Galileo, GPS, and GLONASS, has almost been fully deployed at present. The single point positioning (SPP) technology, which is widely used in satellite navigation and low-accuracy positioning, can benefit from the multiGNSS integration, but the additional intersystem bias (ISB) parameters should be introduced to ensure the compatibility among different GNSSs. In this study, the ISB estimates derived from four-system integrated SPP are carefully characterized, and the performance enhancement attributed to a priori ISB constraints by prediction for position solutions under open sky and constrained visibility environments is rigorously evaluated. The results indicate that the ISB between BDS-3 and BDS-2 cannot be ignored. The daily ISBs show step changes when encountering the replacement of receiver types, while it is not the case for the receiver firmware versions. The daily ISBs are roughly consistent for the stations equipped with the same type of receivers. The short-term stability of epochwise ISBs for GLONASS, Galileo, BDS-2, and BDS-3 with respect to GPS can be 2.335, 1.262, 1.741 , and $1.532 \mathrm{~ns}$, respectively, whereas the corresponding long-term stability for daily ISBs can be $1.258,1.288,2.713$, and $2.566 \mathrm{~ns}$, respectively. The single-day prediction accuracy of daily ISBs for GLONASS, Galileo, BDS-2, and BDS-3 with respect to GPS can be 1.055, 0.640, 1.242, and 0.849 ns, respectively. The improvements on positioning accuracy after introducing a priori ISB constraints can be over $20 \%$ at an elevation mask of $40^{\circ}$ and $50^{\circ}$ with a time span of ISB prediction of a day. As to the availability, it is only $64.0 \%$ for traditional four-system SPP under a cutoff elevation of $50^{\circ}$, while the corresponding availability is increased to approximately $90.0 \%$ after considering a priori ISB constraints. For completeness, the characteristics of ISBs estimated with the low-cost u-blox M8T receiver and the Xiaomi Mi8 smartphone as well as the contribution of a priori ISB constraints to the multisystem SPP solutions with these devices are also investigated.
\end{abstract}

Keywords: single point positioning; intersystem bias; multisystem combination; a priori constraint

\section{Introduction}

Global navigation satellite systems (GNSSs) have experienced rapid development in recent years. Currently, both GPS and GLONASS are in full operation. As for BDS, the official declaration of positioning, navigation, and timing (PNT) services by regional BDS (BDS-2) for the users over the Asia-Pacific regions and by global BDS (BDS-3) for global users was made on 27 December 2012 and on 27 December 2018, respectively. The deployment of Galileo constellation is also progressing rapidly and will be finished in the next few years. As of August 2021, there are 31 GPS satellites, 26 GLONASS satellites, 15 BDS-2 satellites, 34 BDS-3 satellites (including four experimental satellites), and 26 Galileo satellites in orbits. The multisystem combination has been an emerging trend, as 
it can significantly enhance the solutions of satellite-based positioning technology, such as real-time kinematic (RTK) positioning, precise point positioning (PPP) and single point positioning (SPP). This benefits from the increased number and the improved geometry of the visible satellites. Among the satellite-based position services, SPP belongs to the open position service and is widely used in satellite navigation and low-accuracy positioning due to its flexibility, low cost, and simplicity.

Despite the many benefits of multisystem combination, there are still many issues to be solved in the multisystem integrated data processing, especially in the aspect of compatibility among different GNSSs. A bias between observations from different GNSSs can be caused by the distinct time scales employed by them. In addition, the receiverspecific hardware delays are also distinct for different GNSSs. To achieve rigorous multiGNSS position solutions, these intersystem biases (ISBs) must be properly handled. The introduction of additional parameters to estimate the ISBs is a widely used approach. However, this approach will reduce the redundancy of observations. The observations from at least two satellites for each satellite system can theoretically contribute to the solutions of multi-GNSS integrated positioning, which will limit its performance in the extremely constrained visibility environments. When only a satellite for a specific satellite system is available in the multi-GNSS combined processing, the observation residuals of this satellite will equal to zero and the ISB estimates will encounter a deviation from the true value [1].

Many researchers focused on the mitigation of ISB in precise relative positioning. The GPS/Galileo intersystem double-differenced model based on overlapping frequencies L1/E1 and L5/E5a was derived in Odijk and Teunissen [2]. The results indicated that the between-receiver ISB could be ignored for the baseline with two receivers of identical types, while it was not the case for that characterized by different receive types. When the differential ISB was a priori corrected to recover the integer nature of double-differenced ambiguities between different satellite systems, the success rate of short-baseline ambiguity resolution (AR) with different receiver types could be comparable to the case with the same receiver types. Paziewski and Wielgosz [3] also demonstrated that the obvious ISB could not be ignored for the baselines with receivers of different types in GPS/Galileo tightly combined precise relative positioning, and they also validated the benefits for phase AR from the introduction of the known ISBs. In addition, the results indicated that the single-epoch solutions could be achieved at a noise level of 1-2 $\mathrm{mm}$ and decimeters in terms of phase and code ISB, respectively. Tian et al. [4] conducted the ISB estimation for the GPS/BDS-2/Galileo tightly combined RTK. For the code- and phase-specific ISB, the influencing factors included the adopted overlapping frequencies, the firmware versions, and the receiver types. Similarly, the tight combination had the improved position accuracies and successful ambiguity-fixing rates in comparison with the loose combination (differencing the observations within a single satellite system). To identify the estimability of ISB between GPS and Galileo, and GPS and BDS-2, Mi et al. [5] employed the between-receiver single-differenced (SD) multi-GNSS observation equations to formulate the ionosphericfloat, ionospheric-fixed, and ionospheric-weighted models. Based on this SD method, the ISB could be estimated for both overlapping and nonoverlapping frequencies in the RTK processing. Attributed to the reasonable ISB calibration, the multi-GNSS RTK accuracy of the intersystem differencing could be improved by $20-35 \%$, as compared to that of the classical differencing.

Actually, more studies contributed to the estimation and analysis of ISB in PPP. Liu et al. [6] investigated the effects of receiver types, antenna types, and receiver software versions as well as the sources of precise satellite products (namely analysis centers) on the stability of ISB estimates from GPS/BDS-2 combined PPP solutions. Hong et al. [7] adopted the four-system combined PPP to investigate the ISB between GPS and one of GLONASS, Galileo, and BDS-2. The ISB estimates showed systematic deviations (which were nearly identical for different stations) when using the precise products from different analysis centers. Zhang et al. [8] analyzed the long-term characteristics of ISB among GNSSs based 
on uncombined PPP. The standard deviations (STDs) of the relatively stable epochwise ISB over a day for GPS with respect to GLONASS, Galileo, or BDS-2 were less than $0.6 \mathrm{~ns}$, while the variations of the single-day ISB solutions (average value of the epochwise ISB over a day) could be up to $60 \mathrm{~ns}$, which might be attributed to the satellite reference clock of different systems. Zhou et al. [9] comprehensively evaluated the influence of ISB stochastic modeling (constant, random walk process, and white noise process) on the performance of undifferenced and uncombined multisystem (GPS/GLONASS/Galileo/BDS-2/QZSS) integrated PPP with the precise products from different analysis centers. The results indicated that both the positioning accuracy and convergence time were comparable regardless of which ISB strategy was employed when using the precise products from CODE, CNES, and WHU, while the position solutions with constant ISBs showed worse performance among the three ISB strategies when using GFZ products. With the availability of BDS-3 data, several researchers focused on its compatibility with BDS-2. Cao et al. [10] analyzed the ISB estimates between BDS-3 and BDS-2 derived from BDS-3/BDS-2 integrated PPP solutions. No significant day-boundary discontinuities could be found for the ISB estimates, but a difference of several nanoseconds was noted among the stations with the receivers from the same brand. The phase ambiguity estimates, ionospheric delay estimates, and code residuals were obviously affected when ignoring the ISB between BDS-3 and BDS-2, while it was not the case for the positioning accuracies and phase residuals. Zhao et al. [11] also demonstrated that an additional ISB parameter should be introduced into the BDS-2/BDS3 integrated PPP processing due to the different clock references for the precise satellite clock products and the inconsistent code hardware delays between them. Similar to the precise relative positioning, several researchers investigated the contribution of a priori ISB estimates to PPP solutions. Jiang et al. [12] focused on the short-term modeling and prediction of piecewise ISB estimates (every $30 \mathrm{~min}$ ) from GPS/BDS-2 combined PPP. The modeling accuracy was about $0.7 \mathrm{~ns}$, and the prediction accuracy was $0.57-1.21 \mathrm{~ns}$ with the 1-day period. When taking the derived ISBs as a priori constraints, the convergence time of PPP could be reduced by $2.4-19.6 \%$. A tightly coupled model, in which the phase-specific ISB was estimated station-by-station and the resolvable ambiguity between different satellite systems was formed, was proposed by Geng et al. [13] for multi-GNSS PPP AR. The day-to-day scattering was within 0.05 cycles for $85 \%$ of phase-specific ISBs. Compared with the intra-system PPP AR, the initialization time of inter-system PPP AR was reduced by $10 \%$.

Several studies were related to the ISB in SPP processing. Gioia and Borio [14] employed the Allan deviation to validate the stability of ISB in GPS/Galileo combined SPP solutions. In addition, the multi-GNSS navigation performance could degrade when mitigating the ISBs (instead of estimating them) with the time offset parameters provided in the broadcast ephemeris. Zeng et al. [15] focused on the ISB between GPS and BDS-2 derived from their integrated SPP processing. The results indicated that the ISB estimates were receiver-dependent and found to be stable over a day and repeatable over adjacent days based on statistical hypothesis testing. Moreover, the estimated ISBs of BDS-2 geostationary orbit (GEO), inclined geosynchronous orbit (IGSO), and medium earth orbit (MEO) satellites with respect to GPS were consistent. Torre and Caporali [16] performed an analysis of the ISB for multisystem combined SPP using the data sets at nine European stations from four days in 2013. The results indicated that the ISB estimates between GPS and Galileo and between GPS and QZSS were dependent on the employed broadcast or precise ephemeris, while it was not the case for those between GPS and GLONASS.

According to above description, most of the research concentrated on the mitigation and estimation of ISB in precise relative positioning and PPP, while only several studies focused on the ISB in SPP. In addition, the improved accuracy of broadcast ephemeris and the increased number of in-orbit satellites in recent years may leave the conclusions on the SPP-related ISB summarized in the existed studies obsolete. Most importantly, the existed SPP studies did not cover the ISB about BDS-3 satellites. Furthermore, the contribution of a priori ISB estimates to SPP solutions was not rigorously investigated. In this study, 
we carefully characterize the ISB estimates in GPS/GLONASS/Galileo/BDS-3/BDS-2 integrated SPP, and the performance enhancement of ISB estimates as a priori constraints for multisystem SPP position solutions with a prediction period from a day to a week under a cutoff elevation angle from $10^{\circ}$ to $50^{\circ}$ (to simply simulate the harsh observation environments) is rigorously evaluated. The paper starts with the multisystem integrated SPP model taking ISB as a priori constraints. Next, the results are exhibited and analyzed. Subsequently, the discussion is conducted. Finally, the main conclusions are summarized.

\section{Methods}

In this section, the multisystem integrated SPP model taking ISB as a priori constraints is described. Only the code observations on E1 frequency for Galileo, on B1 frequency for BDS, on G1 frequency for GLONASS, and on L1 frequency for GPS are adopted here, since most of the SPP users are still using the low-cost single-frequency receivers. The single-frequency code observations from a GNSS satellite can be modeled as:

$$
P=\rho+c \mathrm{~d} t_{r}-c \mathrm{~d} t+I+T+d_{r}+d
$$

where $P$ is the measured pseudorange, $\rho$ is the geometric range between the phase centers of the satellite and receiver antennas, $c \mathrm{~d} t_{r}$ and $c \mathrm{~d} t$ are the physical clock errors of the receiver and the satellite, respectively, $I$ is the slant ionospheric delay, $T$ is the slant tropospheric delay, and $d_{r}$ and $d$ are the stable code hardware delays at the receiver and the satellite, respectively.

The alignment of time reference and coordinate reference is one of key issues when performing multi-GNSS integrated data processing. The coordinate transformations can be omitted for the SPP processing with a meter-level accuracy, as the difference of coordinate references among different satellite systems (i.e., GTRF for Galileo, CGCS2000 for BDS, PZ90.11 for GLONASS, and WGS-84 for GPS) is confined to several centimeters [16]. By contrast, the difference of the time scales employed by the four GNSSs (i.e., Galileo System Time for Galileo, BDS Time for BDS, GLONASS System Time for GLONASS, and GPS Time for GPS) must be properly considered in the multi-GNSS combined SPP, in view that the effect of the time reference is significant. To mitigate the effect of distinct time scales in the multi-GNSS combined SPP, one receiver clock offset parameter can be estimated for each satellite system. Alternatively, by taking the receiver clock offset parameter of a selected satellite system as the reference, for example, GPS, the additional ISB parameters can be introduced into the code observation equations for other satellite systems. In addition to the distinct time scales, the ISB parameters can also absorb the effect of different receiver-specific code hardware delays among different GNSSs. Due to the inconsistent code hardware delays between BDS-2 and BDS-3 satellites [10,11], an ISB parameter for BDS-2 and an ISB parameter for BDS-3 are estimated. After correcting the ionospheric delay and tropospheric delay with a priori model, fixing the satellite position with broadcast satellite orbits, and correcting the satellite clock offset with broadcast satellite clocks and time group delays (TGDs), the linearized observation model for four-system integrated SPP can be expressed as:

$$
\left\{\begin{array}{l}
p^{G}=\mu^{G} \cdot X+c \mathrm{~d} t_{r, e s t} \\
p^{R}=\mu^{R} \cdot X+c \mathrm{~d} t_{r, e s t}+\operatorname{ISB}^{R, G} \\
p^{E}=\mu^{E} \cdot X+c \mathrm{~d} t_{r, e s t}+\operatorname{ISB}^{E, G} \\
p^{C 2}=\mu^{C 2} \cdot X+c \mathrm{~d} t_{r, e s t}+\operatorname{ISB}^{C 2, G} \\
p^{C 3}=\mu^{C 3} \cdot X+c \mathrm{~d} t_{r, e s t}+\operatorname{ISB}^{C 3, G}
\end{array}\right.
$$

where the superscripts $G, R, E, C 2$, and $C 3$ refer to GPS, GLONASS, Galileo, BDS-2, and BDS-3 satellites, respectively, $p$ is the observed-minus-computed (OMC) code observable, $\mu$ is the unit vector in line-of-sight direction, $X$ is the receiver coordinates in three dimensions (corrections referring to the approximate values), $c \mathrm{~d} t_{r, e s t}$ is the receiver clock estimate grouped with the receiver-specific code hardware delays of GPS, and ISB ${ }^{R, G}$, 
$\mathrm{ISB}^{E, G}, \mathrm{ISB}^{C 2, G}$, and ISB ${ }^{C 3, G}$ denote the ISB parameter between GLONASS and GPS, between Galileo and GPS, between BDS-2 and GPS, and between BDS-3 and GPS, respectively. Actually, a priority list should be made for the selection of reference satellite system for the ISB estimation. When the GPS data are absent, the receiver clock offset parameter of an available satellite system is taken as the reference based on the priority list, and then the ISB parameters are reformulated accordingly for other available satellite systems.

In view that the ISB has a stable characteristic during a short period of time, for example, several days, the estimated ISBs in advance can be used to enhance the multiGNSS integrated SPP solutions by prediction, especially in the much harsh visibility environments. Four pseudo-observation equations are introduced into the traditional observation model of four-system integrated SPP, that is:

$$
\left\{\begin{array}{l}
\delta_{\mathrm{ISB}}^{R, G}=\mathrm{ISB}^{R, G} \\
\delta_{\mathrm{ISB}}^{E, G}=\mathrm{ISB}^{E, G} \\
\delta_{\mathrm{ISB}}^{\mathrm{C} 2, G}=\mathrm{ISB}^{\mathrm{C} 2, G} \\
\delta_{\mathrm{ISB}}^{\mathrm{CS}, G}=\mathrm{ISB}^{\mathrm{C} 3, G}
\end{array}\right.
$$

where $\delta_{\mathrm{ISB}}^{R, G}, \delta_{\mathrm{ISB}}^{E, G}, \delta_{\mathrm{ISB}}^{\mathrm{C2}, G}$, and $\delta_{\mathrm{ISB}}^{\mathrm{C3}, G}$ denote the a priori ISB observable between GLONASS and GPS, between Galileo and GPS, between BDS-2 and GPS, and between BDS-3 and GPS, respectively. In this study, the a priori ISB observable is taken as the average value of the epochwise ISB estimates over a day (with a prediction period of several days).

The estimated parameters include the three-dimensional (3D) receiver coordinates, the receiver clock offset, and the four ISBs, that is:

$$
U=\left[X, c \mathrm{~d} t_{r, e s t}, \operatorname{ISB}^{R, G}, \operatorname{ISB}^{E, G}, \operatorname{ISB}^{C 2, G}, \operatorname{ISB}^{C 3, G}\right]^{\mathrm{T}}
$$

where $U$ is the vector of estimates. As shown in Equation (1), the code observation equation is nonlinear. The estimates in Equation (4) are actually the corrections with respect to the approximate values through an iterative procedure.

Besides the rigorous observation model, a proper stochastic model is also vital for the optimal SPP solutions. Since the quality of observations is highly relevant to the satellite elevation angles, the elevation-dependent weighting scheme is adopted here. Assuming that there is no correlation among the code observations from different satellites (all the nondiagonal elements are equal to zeroes in the covariance matrix of code observations), the variance of code observations from a GNSS satellite can be computed as:

$$
\sigma^{2}(e l e)=\frac{\sigma_{0}^{2}}{(\sin e l e)^{2}}
$$

where $\sigma_{0}$ is the STD of code observations at zenith, which is set to $0.45 \mathrm{~m}$ for GLONASS satellites (mitigating the negative effect of inter-frequency code hardware delay at the receiver) and $0.3 \mathrm{~m}$ for Galileo, GPS, BDS-2 and BDS-3 satellites, and $\sigma(e l e)$ is the STD of code observations at an elevation angle ele. As to the variance of a priori ISB observable, it is taken as the average value of the epochwise variances of ISB estimates over a day (with a prediction period of several days). In this study, the estimator is the least squares adjustment.

\section{Results}

\subsection{Data Sets}

To analyze the ISB characteristics, the data sets collected at 120 globally distributed Multi-GNSS Experiment (MGEX) stations spanning a month from day of year (DOY) 41 to 70 in 2020 are employed. The geographical distribution of the 120 selected MGEX stations is shown in Figure 1, and the receiver types of these stations are listed in Table 1. All the stations can support the GPS/GLONASS/Galileo/BDS-2/BDS-3 data. The selected 
120 stations cover seven different receiver types from three manufacturers. During the analysis period, a total of 29 stations, which are in parentheses in Table 1, encountered a change of receiver firmware versions. In addition, there was a replacement of receiver types for the station UNSA from JAVAD TRE_G3TH to SEPT ASTERX4 on DOY 49 of 2020, and for the station BRUX from SEPT POLARX4TR to SEPT POLARX5TR on DOY 57 of 2020, respectively.

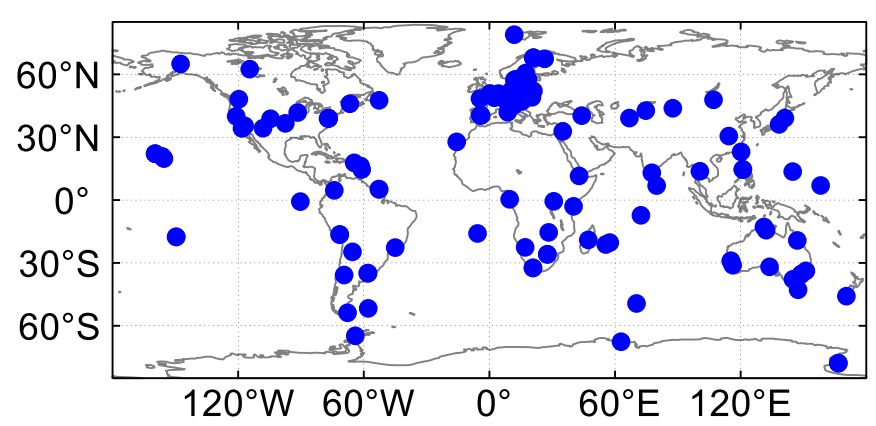

Figure 1. Geographical distribution of the 120 selected MGEX stations.

Table 1. Receiver types of the selected stations.

\begin{tabular}{lll}
\hline Receiver Types & Number & Stations \\
\hline JAVAD TRE_3 & 29 & $\begin{array}{l}\text { SUTM, WIND, WUH2, POTS, URUM, ULAB, NYA2, ZAMB, MBAR, QUIN, } \\
\text { BOGT, CUSV, ARHT, CRO1, GUAM, SOD3, FFMJ, WTZZ, WARN, HUEG, LEIJ, } \\
\text { GODN, GODS, STHL, POL2, BSHM, (SGOC, SGPO, LPGS) }\end{array}$ \\
\hline JAVAD TRE_G3TH & 12 & $\begin{array}{l}\text { MADR, GOLD, MCM4, PALM, GLPS, PIMO, PIE1, HRAO, FAIR, KOKV, AREQ, } \\
\text { UNSA (DOY 41-48, 2020) }\end{array}$ \\
\hline SEPT ASTERX4 & 3 & MIZU, OUS2, UNSA (DOY 49-70, 2020) \\
\hline SEPT POLARX4TR & 5 & MOBS, SYDN, AGGO, OP71, BRUX (DOY 41-56, 2020) \\
\hline SEPT POLARX5 & 45 & \begin{tabular}{l} 
MAW1, MAR6, VIS0, USUD, JPLM, ARUC, DGAR, IISC, FALK, ABPO, SUTH, \\
DARW, HAL1, MKEA, VACS, KIR0, MAO0, MAL2, FAA1, MAS1, REUN, PTGG, \\
AJAC, CHPI, KIRU, REDU, VILL, JOZE, KOUR, (CEDU, HOB2, TID1, STR1, \\
POHN, YAR3, KAT1, TOW2, GRAZ, YARR, ABMF, AREG, DJIG, NKLG, KITG, \\
PADO) \\
\hline SEPT POLARX5TR
\end{tabular} \\
\hline TRIMBLE ALLOY & $\begin{array}{l}\text { ONSA, GODE, BREW, KOKB, NLIB, SPT0, MGUE, CEBR, NNOR, AMC4, BRUX } \\
\text { (DOY 57-70, 2020), (HERS, THTG, KOUG, PTBB, STJ3, YEL2, USN7, HARB) }\end{array}$ \\
\hline
\end{tabular}

\subsection{Characteristics of ISB Estimates}

The characteristics of ISB estimates derived from GPS/GLONASS/Galileo/BDS2 /BDS-3 integrated SPP under a cutoff elevation angle of $10^{\circ}$ are rigorously investigated in this section. Figure 2 illustrates the epochwise ISB estimates at stations KIRU and PTBB on DOY 41 of 2020. It is seen that all the four groups of ISB estimates are relatively stable with a varying range of approximately $10 \mathrm{~ns}$. Most importantly, the ISB estimates for BDS-2 and BDS-3 with respect to GPS show obvious differences by several nanoseconds, indicating that the arrangement of only an ISB parameter for both BDS-2 and BDS-3 satellites is unreasonable. 


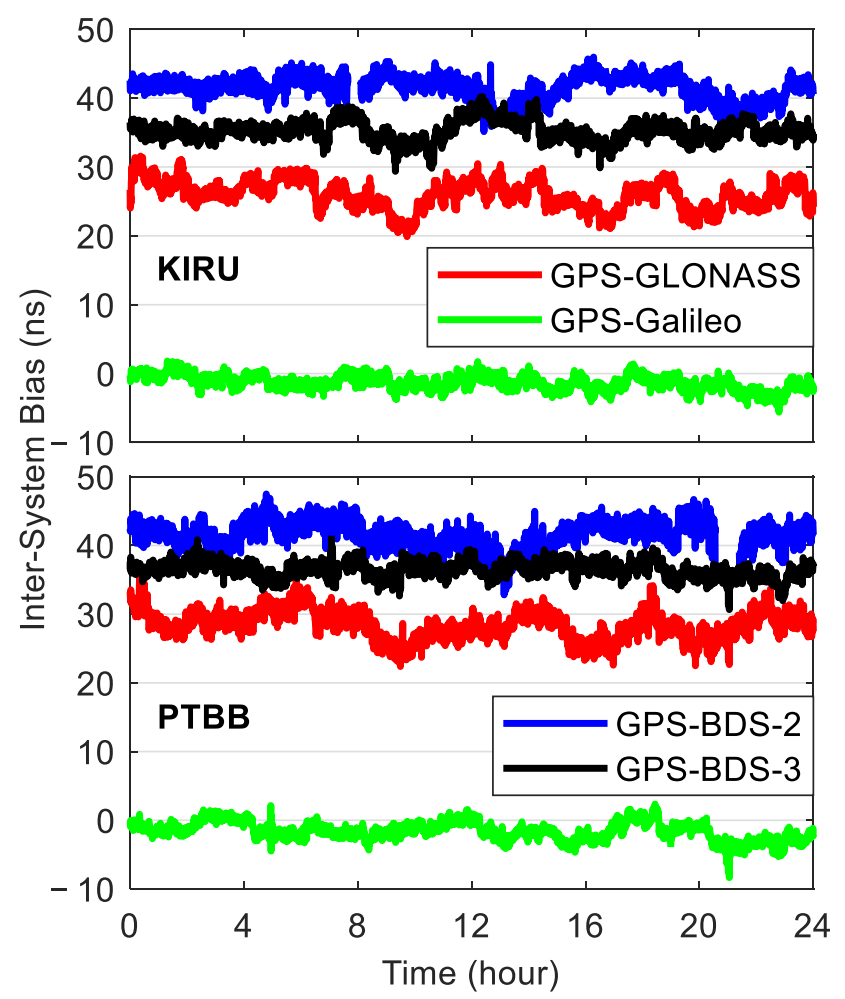

Figure 2. Epochwise ISB estimates at stations KIRU and PTBB on DOY 41 of 2020.

To investigate whether the receiver firmware versions can affect the ISB estimation, Figure 3 exhibits the time series of daily ISBs (i.e., the average value of the epochwise ISB estimates over a day) at 29 stations, which encounter a change of receiver firmware versions. Different stations are identified by the distinct colors. When the curves turn into dotted lines, it means that the receiver firmware versions are changed. To be reliable, the epochwise ISB estimates with a visible satellite number below 3 are discarded, and the daily ISBs are calculated only when the number of available epochwise ISB estimates is more than 500 (i.e., $250 \mathrm{~min}$ ). As shown in Figure 3, the daily ISBs are partially absent for several stations, which can be attributed to the absence of observations or the insufficient epochwise ISB estimates. As we can see, the daily ISBs do not present obvious fluctuations when the receiver firmware versions are changed. Thus, the effects of receiver firmware versions on the ISB estimation are not significant. In addition, the time series of daily ISBs between Galileo and GPS at two stations (KRGG and UNB3), between BDS-2 and GPS at a station (KRGG), and between BDS-3 and GPS at two stations (KRGG and UNB3) show obvious differences with respect to those at the other stations, in view that the ISB estimates are dependent on the receiver types, which will be validated in this section, and both the two stations are equipped with the TRIMBLE ALLOY receiver. There may be other influencing factors for the distinct ISB series between GLONASS and GPS at a station (CEDU), such as the temperature and other environmental factors, which needs to be investigated further. 

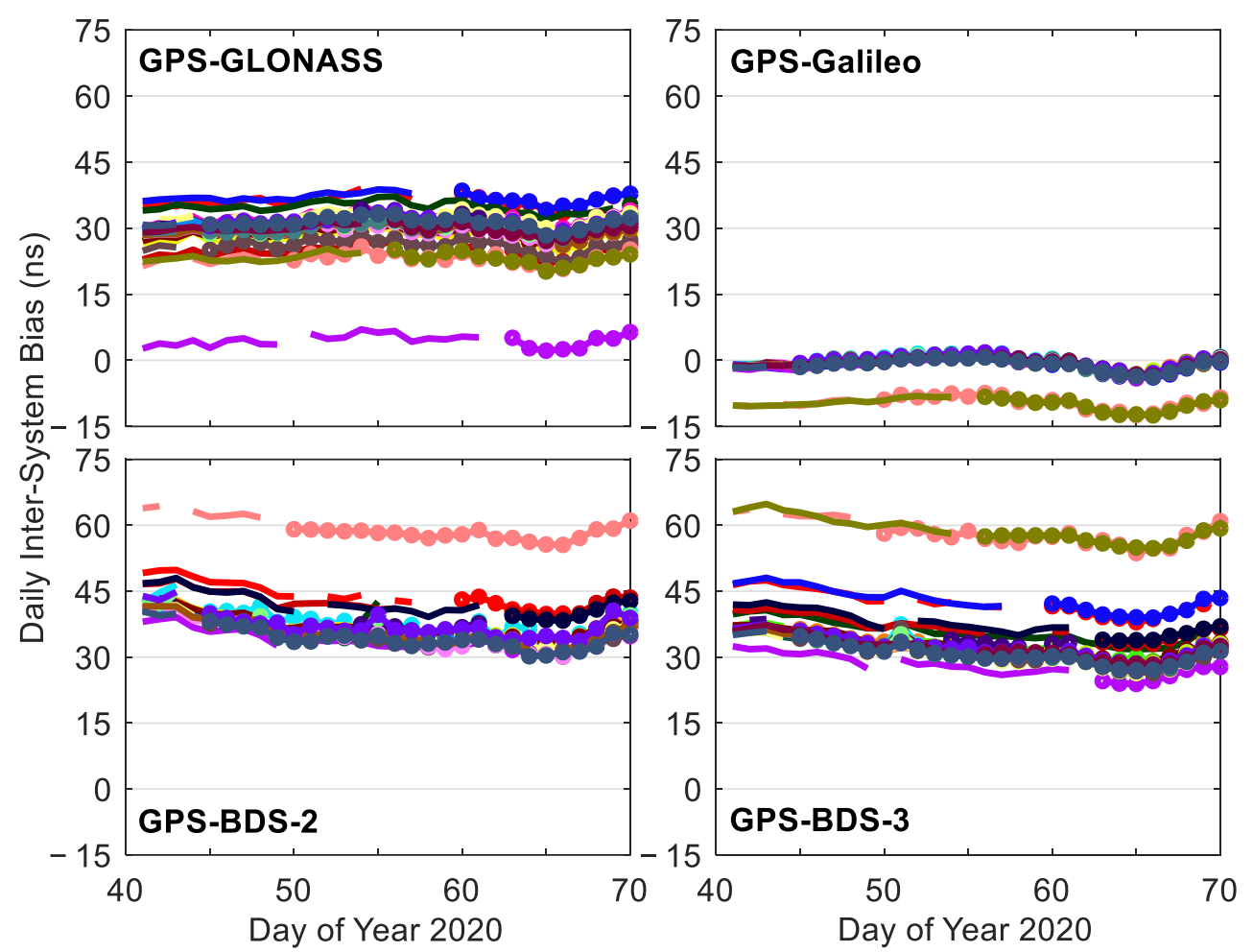

Figure 3. Time series of daily ISBs at 29 stations (characterized by the change of receiver firmware versions).

To investigate whether the receiver types can affect the ISB estimation, Figure 4 shows the time series of daily ISBs at BRUX (red) and UNSA (blue) stations, which encounter a replacement of receiver types. It implies that the receiver types are replaced when the curves turn into dotted lines. As the station UNSA is located in South America (outside the service regions of BDS-2), the daily ISBs between BDS-2 and GPS at this station are unavailable. It is seen that the daily ISBs between Galileo and GPS at both BRUX and UNSA stations as well as those between GLONASS and GPS at UNSA station do not present step changes when encountering the replacement of receiver types. However, the step changes can be up to 13, 9, and 10 ns for the daily ISBs between GLONASS and GPS, between BDS-2 and GPS, and between BDS-3 and GPS at BRUX station, and to $17 \mathrm{~ns}$ for the daily ISBs between BDS-3 and GPS at UNSA station when the receiver types are replaced, respectively. Thus, the effects of receiver types on the ISB estimation cannot be neglected.

For the purpose of analyzing the short-term stability of ISB, Figure 5 depicts the distribution of STDs of epochwise ISB estimates over a day based on the data sets from 120 stations spanning a month. The single-day STDs of epochwise ISBs with a value smaller than 1, 2, 3, and 4 ns account for $0.0 \%, 26.4 \%, 90.7 \%$, and $99.7 \%$ for those between GLONASS and GPS, for $16.5 \%, 97.9 \%, 99.8 \%$, and $100.0 \%$ for those between Galileo and GPS, for $5.9 \%, 72.6 \%, 96.2 \%$, and $99.4 \%$ for those between BDS- 2 and GPS, and for $3.5 \%$, $91.5 \%, 98.1 \%$, and $99.2 \%$ for those between BDS-3 and GPS, respectively. The average results over all the employed stations and days are also provided in each panel. As we can see, the ISBs between Galileo and GPS achieve the best short-term stability with an average STD statistic of $1.262 \mathrm{~ns}$, followed by those between BDS-3 and GPS, the average STDs of which are $1.532 \mathrm{~ns}$. The short-term stability of ISBs between BDS-2 and GPS is worse than that between BDS-3 and GPS, and the corresponding STDs are increased to $1.741 \mathrm{~ns}$. Among the four groups of ISBs, the one between GLONASS and GPS has the lowest short-term stability with an average STD statistic of $2.335 \mathrm{~ns}$. 


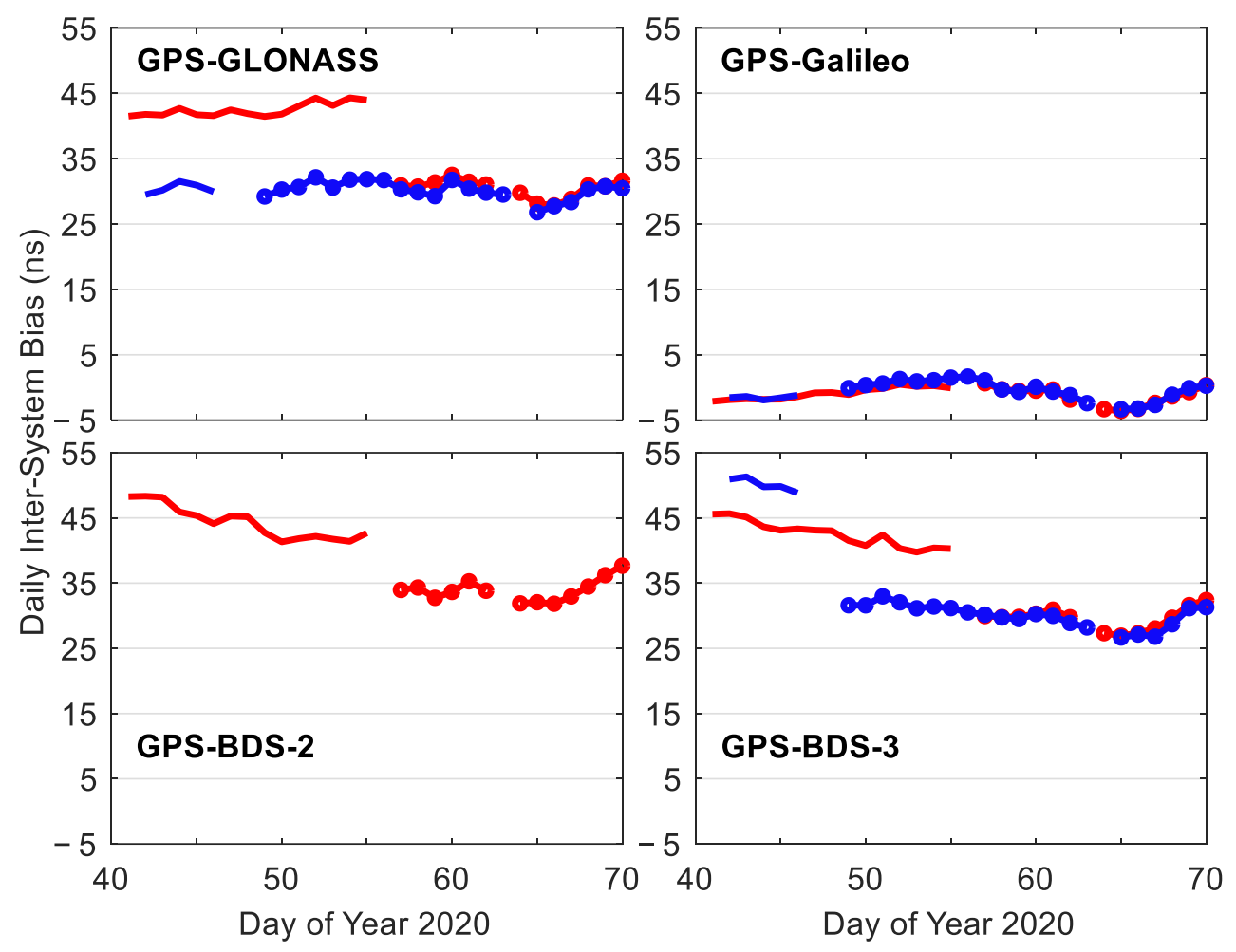

Figure 4. Time series of daily ISBs at BRUX (red) and UNSA (blue) stations (characterized by the replacement of receiver types).

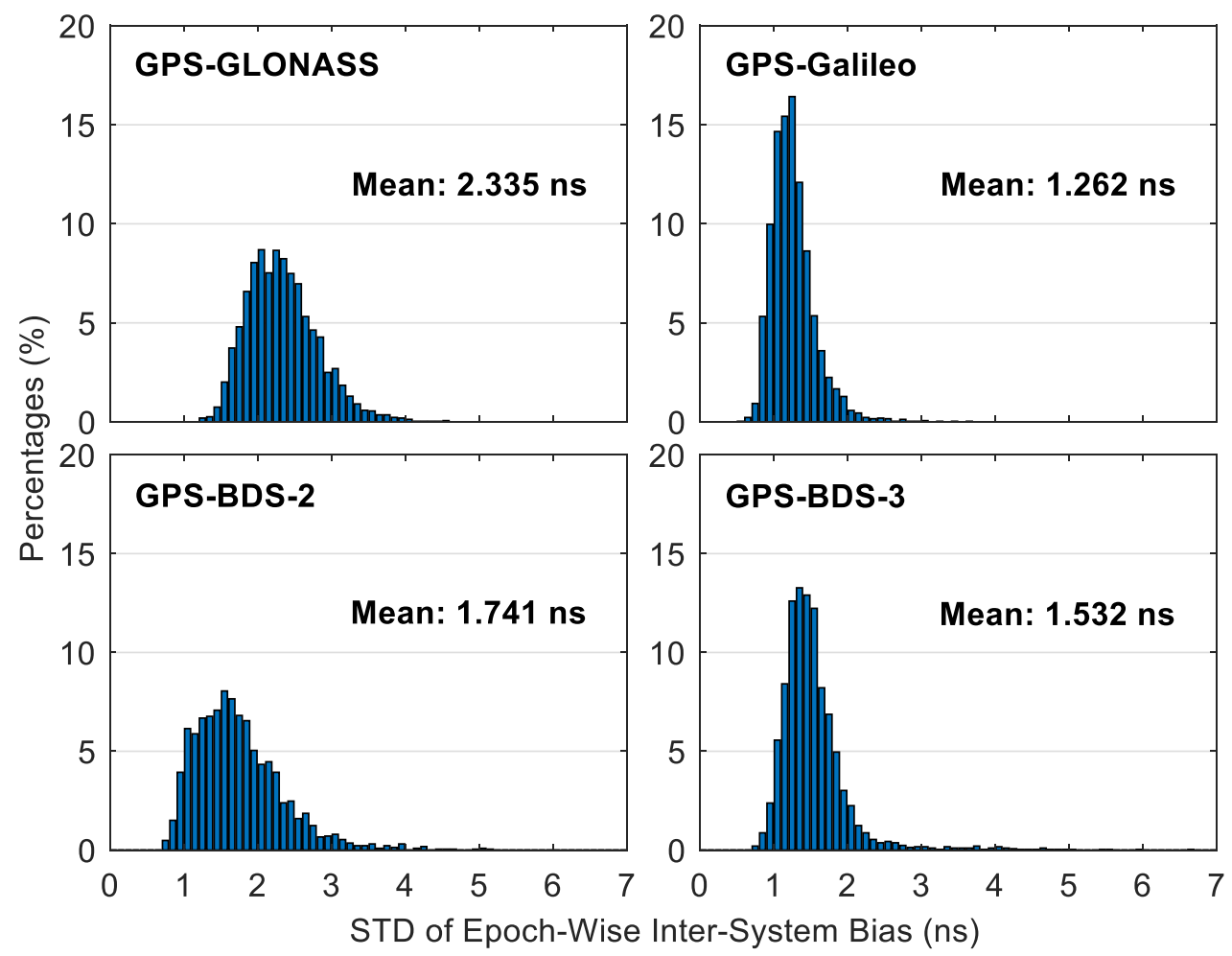

Figure 5. Distribution of STDs of epochwise ISB estimates over a day based on the data sets from 120 stations spanning a month.

To investigate the effects of receiver types on the short-term stability of ISBs, we calculate the average value of STDs of epochwise ISB estimates over a day for all the 
stations equipped with the same type of receivers using the data sets from DOY 41 to 70 in 2020, and the results for each receiver type are given in Figure 6. It is seen that, except for the ISB results between BDS-3 and GPS for TRIMBLE ALLOY receiver, the JAVAD TRE_G3TH receiver achieves worse short-term stability for all the four groups of ISBs. However, the difference of the short-term stability of ISBs among different receiver types is not very significant, which is confined to approximately $0.5,0.2,1.0$, and $0.5 \mathrm{~ns}$ for the ISBs between GLONASS and GPS, between Galileo and GPS, between BDS-2 and GPS, and between BDS-3 and GPS, respectively.

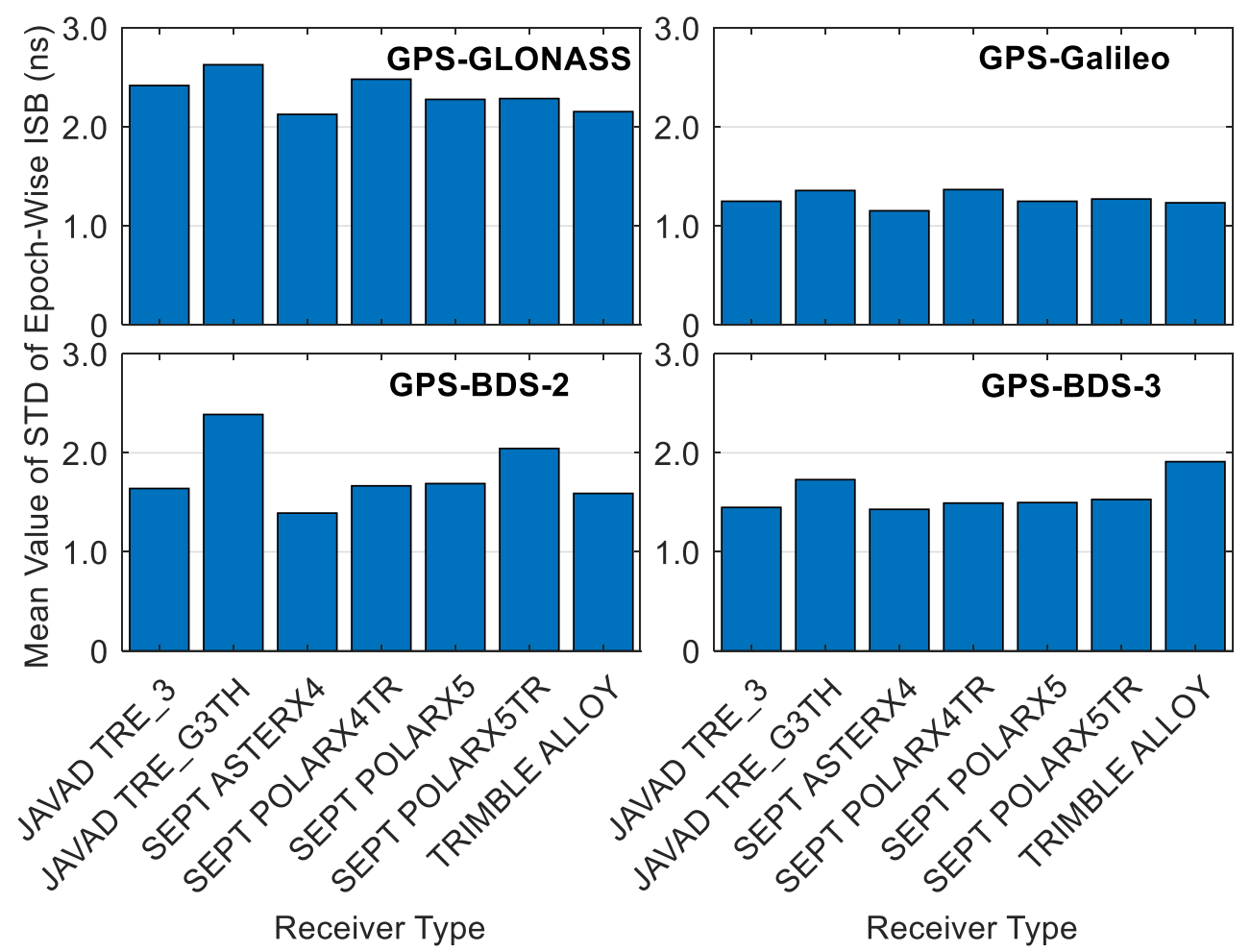

Figure 6. Average value of STDs of epochwise ISB estimates over a day for each receiver type based on the data sets from 120 stations spanning a month.

To explore the relationship between the numerical values of ISB (i.e., the magnitude of ISB) and the receiver types, Figure 7 presents the time series of daily ISBs (i.e., the average value of the epochwise ISB estimates over a day) for each station on DOY 41-70, 2020. Different colors refer to different receiver types, and some ones are with marks (dots) for clarity. The two stations encountering the receiver replacement, namely BRUX and UNSA, are not included in the analysis here. As can be seen, the daily ISBs are roughly consistent for the stations equipped with the same type of receivers, except for those between GLONASS and GPS at station CEDU. For the daily ISBs between Galileo and GPS, their difference among the stations within the same receiver type is usually confined to $2 \mathrm{~ns}$, and similar situations can also be found for the other three groups of daily ISBs at the stations with the TRIMBLE ALLOY receiver (nine stations) as well as the stations with the SEPT ASTERX4 receiver (only two stations). The difference of daily ISBs between BDS-2 and GPS and between BDS-3 and GPS among the stations within the same receiver type varies within $10 \mathrm{~ns}$ for most of the time for all the JAVAD TRE_3, JAVAD TRE_G3TH, SEPT POLARX4TR, SEPT POLARX5, and SEPT POLARX5TR receivers. As for the daily ISBs between GLONASS and GPS, the corresponding varying range of difference is $10 \mathrm{~ns}$ for the JAVAD TRE_3, SEPT POLARX4TR, and SEPT POLARX5TR receivers, and $20 \mathrm{~ns}$ for the JAVAD TRE_G3TH and SEPT POLARX5 receivers, respectively. The numerical values range from 20 to $45 \mathrm{~ns}$ for the daily ISBs between GLONASS and GPS (except for the station CEDU), from 30 to $70 \mathrm{~ns}$ for the daily ISBs between BDS-2 and GPS, and from 
25 to $65 \mathrm{~ns}$ for the daily ISBs between BDS-3 and GPS, respectively, while the numerical values of daily ISBs between Galileo and GPS range from -3 to $-7 \mathrm{~ns}$ for the stations with the TRIMBLE ALLOY receiver, and from -5 to $3 \mathrm{~ns}$ for the stations with the other six types of receivers, respectively. In addition, the time series of daily ISBs within the same group exhibit consistent trends, which may be attributed to the jointly employed broadcast ephemeris.
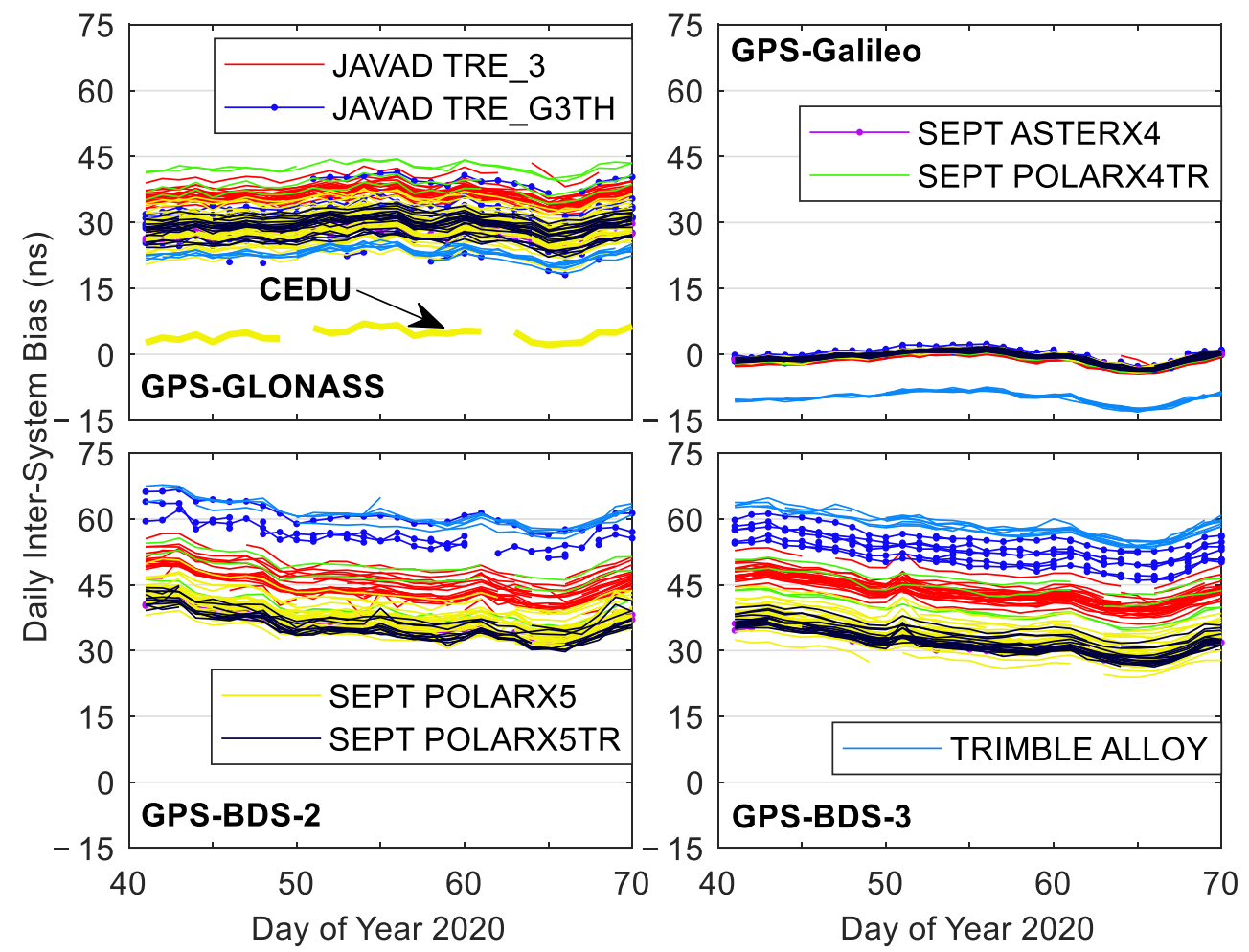

Figure 7. Time series of daily ISBs for each station (characterized by the receiver types) on DOY 41-70, 2020.

To investigate the long-term stability of ISB, Figure 8 presents the STD statistics of daily ISBs (i.e., the average value of the epochwise ISB estimates over a day) over a month (i.e., DOY 41 to 70 in 2020) for each station. The stations with different receiver types are identified by different colors. The two stations encountering the receiver replacement are removed from the analysis here, and the STDs at a station are computed only when at least ten days of daily ISBs at this station are available, to derive reliable statistics. Thus, the STD statistics of daily ISBs are absent for some stations in Figure 8, especially for those between BDS-2 and GPS. As we can see, the effects of receiver types on the long-term stability of ISB are marginal. Different from the short-term stability of ISB, the daily ISBs between GLONASS and GPS achieve the best long-term stability with a STD statistic of $1.258 \mathrm{ns,}$ followed by those between Galileo and GPS with a slightly larger STD statistic of $1.288 \mathrm{~ns}$. The daily ISBs between BDS-2 and GPS and between BDS-3 and GPS have significantly worse long-term stability, and the corresponding STD statistics are approximately twice as large as those between GLONASS and GPS and between Galileo and GPS, which are 2.713 and $2.566 \mathrm{~ns}$, respectively. 


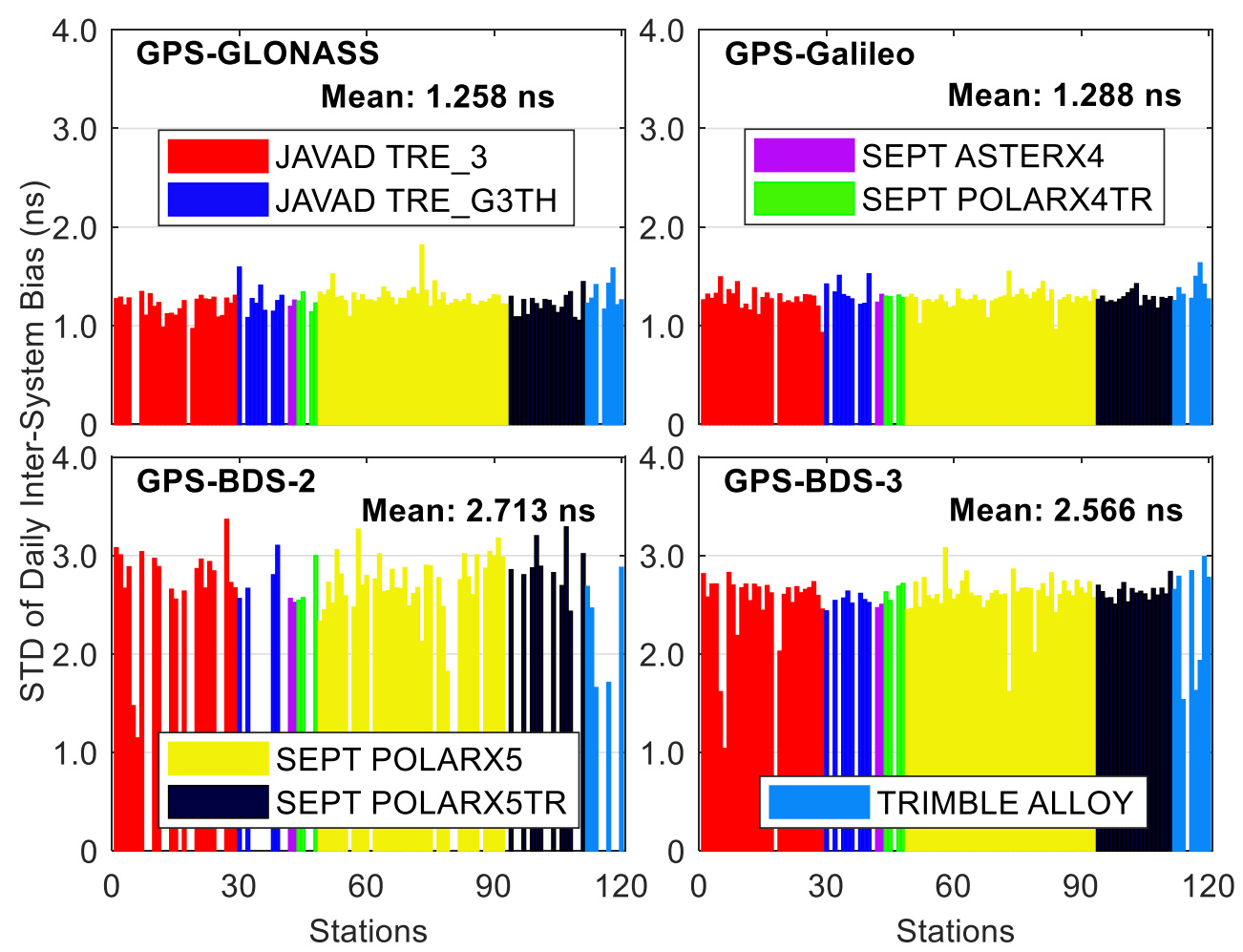

Figure 8. STD statistics of daily ISBs over a month for each station (characterized by the receiver types).

\subsection{Prediction of Daily ISBs}

As the daily ISBs (i.e., the average value of the epochwise ISB estimates over a day) have a good long-term stability (see Figures 7 and 8), they can be used as a priori constraints by prediction to improve the performance of multisystem combined SPP (real-time data processing). The prediction performance of daily ISBs is assessed in this section. In view that the epochwise ISB estimates are susceptible to various errors and show stable characteristics over a day (see Figure 2), the daily ISBs rather than the epochwise ISBs are employed. Figure 9 illustrates the prediction residuals of daily ISBs for each station on DOY 41-70 of 2020 when the time span of prediction is set to a day. The two stations encountering the receiver replacement are not included in the analysis here. Different receiver types are identified by different colors and marks. The single-day prediction residuals of daily ISBs between Galileo and GPS and between BDS-3 and GPS usually vary within $2 \mathrm{~ns}$, while the corresponding varying range is expanded to 3 and $4 \mathrm{~ns}$ for those between GLONASS and GPS and between BDS-2 and GPS, respectively. In addition, the single-day prediction residuals of daily ISBs within the same group for the stations with various receiver types are comparable to each other, which is further validated by the similar root mean square (RMS) statistics of the corresponding prediction residuals for each receiver type (see Figure 10). The RMS statistics of single-day prediction residuals of daily ISBs over all the employed stations and days are provided in each panel in Figure 9. The single-day prediction accuracy of daily ISBs between GLONASS and GPS, between Galileo and GPS, between BDS-2 and GPS, and between BDS-3 and GPS can be 1.055, 0.640, 1.242 , and $0.849 \mathrm{~ns}$, respectively. 


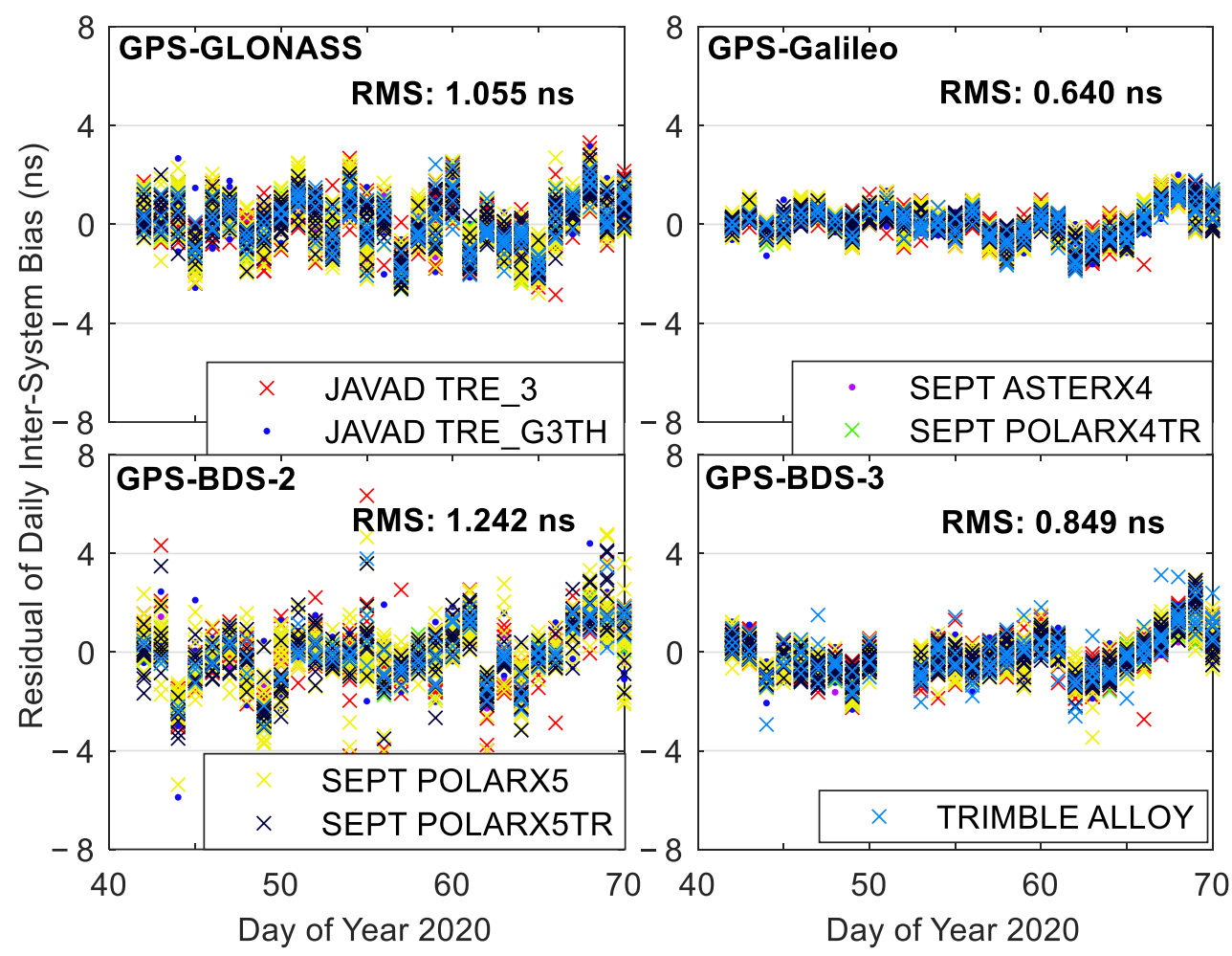

Figure 9. Prediction residuals of daily ISBs with a time span of prediction of a day for each station (characterized by the receiver types).
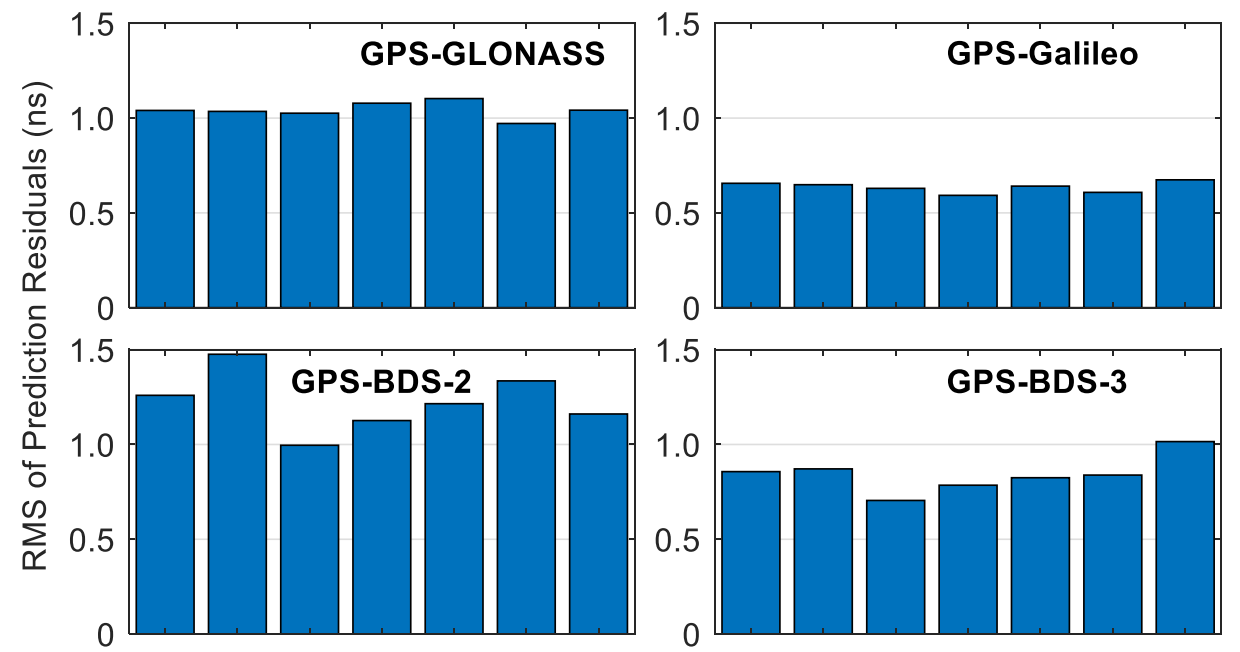

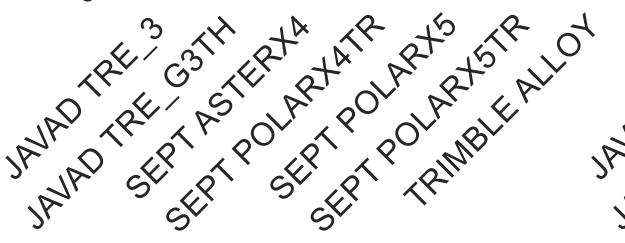

Receiver Type

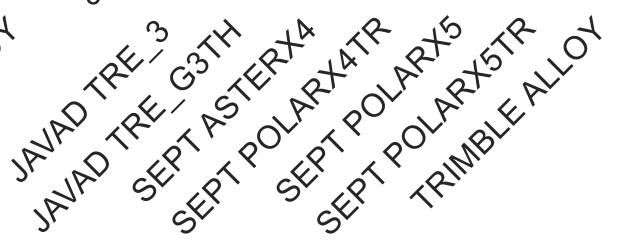

Receiver Type

Figure 10. RMS statistics of prediction residuals of daily ISBs with a time span of prediction of a day for each receiver type.

For further analysis, Table 2 provides the prediction accuracy of daily ISBs based on the data sets of all the employed stations and days when the time span of prediction is lengthened to 2-7 days. As we can see, the prediction accuracy of daily ISBs degrades with the increasing time span of prediction, especially for those between BDS-2 and GPS and 
between BDS-3 and GPS. When the time span of prediction is set to a week, a prediction accuracy of $1.767,1.954,2.982$, and $2.580 \mathrm{~ns}$ can still be achieved for the daily ISBs between GLONASS and GPS, between Galileo and GPS, between BDS-2 and GPS, and between BDS-3 and GPS, respectively.

Table 2. Prediction accuracy of daily ISBs with a time span of prediction of 2-7 days.

\begin{tabular}{ccccc}
\hline \multirow{2}{*}{$\begin{array}{c}\text { Time Span of } \\
\text { Prediction }\end{array}$} & \multicolumn{4}{c}{ Accuracy of Predicted ISBs (ns) } \\
\cline { 2 - 5 } & GPS-GLONASS & GPS-Galileo & GPS-BDS-2 & GPS-BDS-3 \\
\hline 2 days & 1.377 & 1.054 & 1.856 & 1.444 \\
3 days & 1.691 & 1.368 & 2.297 & 1.878 \\
4 days & 1.759 & 1.605 & 2.522 & 2.156 \\
5 days & 1.859 & 1.758 & 2.667 & 2.322 \\
6 days & 1.819 & 1.867 & 2.831 & 2.471 \\
7 days & 1.767 & 1.954 & 2.982 & 2.580 \\
\hline
\end{tabular}

As the numerical values differ among the four groups of daily ISBs (see Figure 7), the correction rate is further taken as an index to evaluate the prediction performance of daily ISBs. The differences between the RMS statistics of ISB estimate series and of ISB prediction residual series are first obtained, and the correction rates are then determined as the ratio between the differences and the RMS statistics of ISB estimate series. The derived results of correction rates are provided in Table 3. Similar to the prediction accuracy of daily ISBs, the correction rates decrease with the increment of the time span of prediction. Despite this, the correction rates of predicted daily ISBs are still larger than $94.0 \%$ for those between GLONASS and GPS and larger than 93.0\% for those between BDS-2 and GPS and between BDS-3 and GPS, respectively, when the time span of prediction is as long as seven days. Due to the small numerical values of daily ISBs between Galileo and GPS (see Figure 7), the correction rates are only $78.0 \%$, even when the time span of prediction is set to a day, and decrease to $32.8 \%$ with a time span of prediction of a week.

Table 3. Correction rate of predicted daily ISBs with a time span of prediction from a day to seven days.

\begin{tabular}{ccccc}
\hline \multirow{2}{*}{$\begin{array}{c}\text { Time Span of } \\
\text { Prediction }\end{array}$} & \multicolumn{3}{c}{ Correction Rate of Predicted ISBs } \\
\cline { 2 - 4 } & GPS-GLONASS & GPS-Galileo & GPS-BDS-2 & GPS-BDS-3 \\
\hline 1 day & $96.6 \%$ & $78.0 \%$ & $97.1 \%$ & $97.9 \%$ \\
2 days & $95.6 \%$ & $63.8 \%$ & $95.6 \%$ & $96.4 \%$ \\
3 days & $94.6 \%$ & $53.0 \%$ & $94.6 \%$ & $95.3 \%$ \\
4 days & $94.4 \%$ & $44.8 \%$ & $94.0 \%$ & $94.6 \%$ \\
5 days & $94.1 \%$ & $39.5 \%$ & $93.7 \%$ & $94.2 \%$ \\
6 days & $94.2 \%$ & $35.8 \%$ & $93.3 \%$ & $93.8 \%$ \\
7 days & $94.3 \%$ & $32.8 \%$ & $93.0 \%$ & $93.5 \%$ \\
\hline
\end{tabular}

\subsection{Performance of Four-System Integrated SPP with a Priori ISB Constraints}

In this section, the performance of four-system integrated SPP with a priori ISB constraints is rigorously evaluated. For comparison, eight different situations are employed for the four-system SPP processing. In the first case, the a priori ISB constraint is not considered (i.e., traditional four-system SPP processing). For the following seven cases, the a priori ISBs are obtained by prediction with the daily ISB estimates of the last 1-7 days. In addition, as the developed SPP model is mainly for the data processing under the constrained visibility environments, the elevation mask angle is set from $20^{\circ}$ to $50^{\circ}$ in steps of $10^{\circ}$ to simply simulate the real harsh environments. For completeness, the four-system SPP processing at a cutoff elevation of $10^{\circ}$ is also conducted. The data sets collected at all the 120 stations (except for the two stations encountering a replacement of receiver types) 
spanning a week from DOY 48 to 54 of 2020 are used for the performance analysis of the four-system SPP.

Figure 11 illustrates the epochwise positioning errors of four-system integrated SPP with and without a priori ISB constraints under a cutoff elevation of $50^{\circ}$ at station ABMF on DOY 48 of 2020. For clarity, only the results of the two cases with a time span of ISB prediction of a day and seven days for the four-system SPP considering a priori ISB constraints are presented in Figure 11. As we can see, the SPP solutions without a priori ISB constraints at station ABMF are unavailable for a lot of epochs under extremely harsh environments, even though the observations from GPS, GLONASS, Galileo, BDS-2, and BDS-3 are jointly used. In addition, the epochwise position errors show many spikes, and can be over 20,20, and $30 \mathrm{~m}$ in the east, north, and up directions, respectively. By contrast, after taking the a priori ISB constraints into consideration, both the availability and the positioning accuracy of four-system SPP solutions are significantly improved. About $80 \%$ of the position solutions become available with an epochwise positioning error usually varying within 10,10 , and $30 \mathrm{~m}$ in the three directions, respectively, even when the time span of ISB prediction is set to as long as a week.
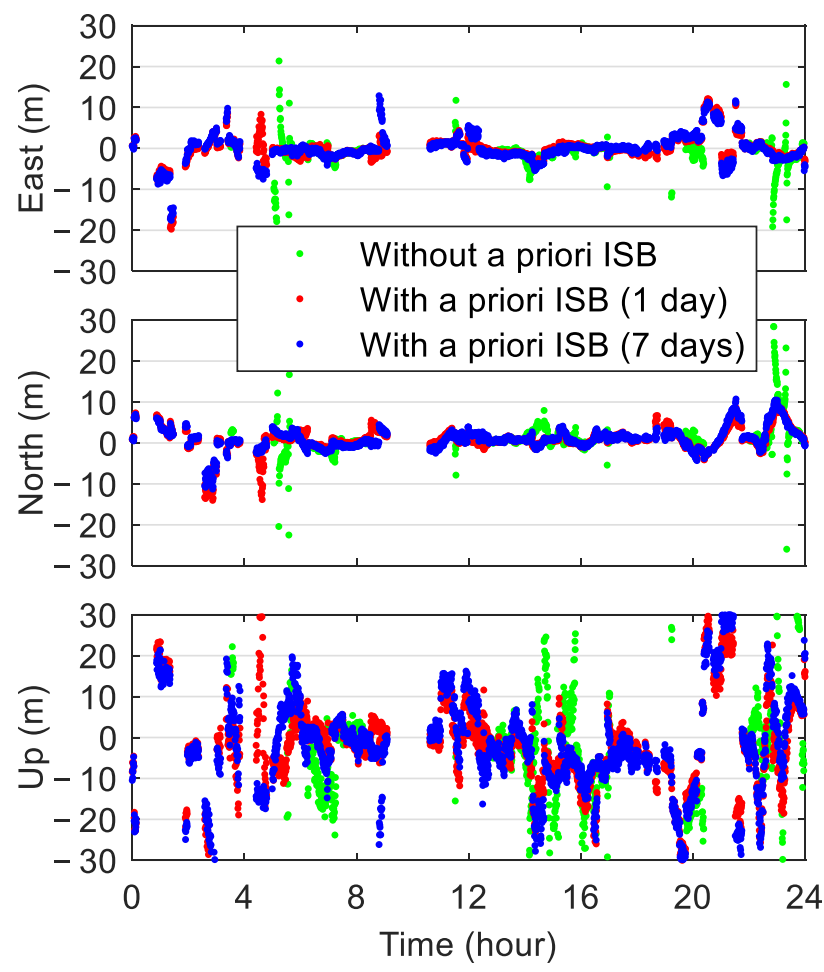

Figure 11. Epochwise positioning errors of four-system integrated SPP with and without a priori ISB constraints under a cutoff elevation of $50^{\circ}$ at station ABMF on DOY 48 of 2020.

For further analysis, Table 4 lists the position accuracy in (m) of four-system integrated SPP with and without a priori ISB constraints under different elevation masks. The improvement rates of the positioning accuracy in $(\mathrm{m})$ for the seven four-system SPP cases considering a priori ISB constraints over the one ignoring a priori ISB constraints under different elevation masks are presented in Table 5 . The positioning accuracy is taken as the RMS statistics of epochwise positioning errors over all the available epochs (from all the employed stations and days in this section) for each four-system SPP processing case. As we can see, when the cutoff elevations are lower than or equal to $30^{\circ}$, the accuracy improvements that benefit from the a priori ISB constraints are marginal (less than 10\%), and the positioning accuracy in the east direction with a time span longer than or equal to four days for ISB prediction even slightly degrades after considering the a priori ISB constraints. This implies that there are sufficient visible satellites for four-system integrated SPP even when the elevation masks are increased to $30^{\circ}$. By contrast, when the elevation 
masks are further increased to $40^{\circ}$ and $50^{\circ}$, the accuracy improvements coming with the a priori ISB constraints become significant. The improvements on the positioning accuracy after introducing the a priori ISB constraints can be $22 \%, 27 \%, 24 \%$, and $24 \%$ and $25 \%, 26 \%$, $23 \%$, and $23 \%$ at an elevation mask of $40^{\circ}$ and $50^{\circ}$ with a time span of ISB prediction of a day in the east, north, up, and $3 \mathrm{D}$ directions, respectively. Under a cutoff elevation of $40^{\circ}$ and $50^{\circ}$, the improvement rates decrease with the increasing time span of ISB prediction, and the corresponding accuracy improvements attributed to the a priori ISB constraints with a time span of ISB prediction of seven days can still be $8 \%, 20 \%, 12 \%$, and $13 \%$ and $12 \%, 17 \%, 6 \%$, and $7 \%$ in the four directions, respectively. When the time span of ISB prediction is only a day, the positioning accuracy of four-system SPP with a priori ISB constraints at an elevation mask of $10^{\circ}$ to $30^{\circ}$ does not show an obvious difference, which is confined to $8,6,15$, and $16 \mathrm{~cm}$ in the four directions, respectively, and can be $0.517-0.600$, $0.846-0.910,2.549-2.696$, and $2.735-2.897 \mathrm{~m}$ in the four directions, respectively. When the cutoff elevations are increased to $40^{\circ}$ and $50^{\circ}$, the positioning accuracy of four-system SPP considering a priori ISB constraints with a time span of ISB prediction of a day significantly degrades, but it can still be $0.856,1.239,3.728$, and $4.020 \mathrm{~m}$ and 1.574, 2.346, 7.128, and $7.667 \mathrm{~m}$ in the four directions, respectively.

Table 4. Positioning accuracy in (m) of four-system integrated SPP with and without a priori ISB constraints under different elevation masks.

\begin{tabular}{|c|c|c|c|c|c|c|}
\hline \multirow{2}{*}{ Strategy } & \multirow{2}{*}{ Directions } & \multicolumn{5}{|c|}{ Elevation Mask Angles } \\
\hline & & $10^{\circ}$ & $20^{\circ}$ & $30^{\circ}$ & $40^{\circ}$ & $50^{\circ}$ \\
\hline \multirow{4}{*}{$\begin{array}{l}\text { Without A } \\
\text { Priori ISB }\end{array}$} & East (m) & 0.537 & 0.543 & 0.642 & 1.092 & 2.103 \\
\hline & North (m) & 0.933 & 0.890 & 1.001 & 1.699 & 3.162 \\
\hline & $\mathrm{Up}(\mathrm{m})$ & 2.804 & 2.688 & 2.964 & 4.911 & 9.238 \\
\hline & $3 \mathrm{D}(\mathrm{m})$ & 3.003 & 2.883 & 3.193 & 5.310 & 9.988 \\
\hline \multirow{4}{*}{$\begin{array}{l}\text { With A } \\
\text { Priori ISB } \\
\text { (1 day) }\end{array}$} & East $(\mathrm{m})$ & 0.522 & 0.517 & 0.600 & 0.856 & 1.574 \\
\hline & North (m) & 0.906 & 0.846 & 0.910 & 1.239 & 2.346 \\
\hline & $\mathrm{Up}(\mathrm{m})$ & 2.696 & 2.549 & 2.684 & 3.728 & 7.128 \\
\hline & $3 \mathrm{D}(\mathrm{m})$ & 2.892 & 2.735 & 2.897 & 4.020 & 7.667 \\
\hline \multirow{4}{*}{$\begin{array}{l}\text { With A } \\
\text { Priori ISB } \\
\text { (2 days) }\end{array}$} & East (m) & 0.532 & 0.529 & 0.614 & 0.873 & 1.612 \\
\hline & North (m) & 0.907 & 0.849 & 0.918 & 1.249 & 2.384 \\
\hline & $\mathrm{Up}(\mathrm{m})$ & 2.690 & 2.548 & 2.702 & 3.792 & 7.321 \\
\hline & $3 \mathrm{D}(\mathrm{m})$ & 2.888 & 2.737 & 2.919 & 4.086 & 7.866 \\
\hline \multirow{4}{*}{$\begin{array}{l}\text { With A } \\
\text { Priori ISB } \\
\text { (3 days) }\end{array}$} & East (m) & 0.537 & 0.536 & 0.627 & 0.895 & 1.648 \\
\hline & North (m) & 0.908 & 0.852 & 0.926 & 1.264 & 2.416 \\
\hline & $\mathrm{Up}(\mathrm{m})$ & 2.695 & 2.553 & 2.727 & 3.860 & 7.526 \\
\hline & $3 \mathrm{D}(\mathrm{m})$ & 2.894 & 2.745 & 2.947 & 4.159 & 8.075 \\
\hline \multirow{4}{*}{$\begin{array}{l}\text { With A } \\
\text { Priori ISB } \\
\text { (4 days) }\end{array}$} & East (m) & 0.545 & 0.546 & 0.638 & 0.915 & 1.676 \\
\hline & North (m) & 0.906 & 0.853 & 0.928 & 1.270 & 2.434 \\
\hline & $\mathrm{Up}(\mathrm{m})$ & 2.705 & 2.569 & 2.768 & 3.939 & 7.695 \\
\hline & 3D (m) & 2.904 & 2.762 & 2.988 & 4.239 & 8.243 \\
\hline \multirow{4}{*}{$\begin{array}{l}\text { With A } \\
\text { Priori ISB } \\
\text { (5 days) }\end{array}$} & East (m) & 0.556 & 0.563 & 0.658 & 0.941 & 1.739 \\
\hline & North (m) & 0.913 & 0.865 & 0.947 & 1.305 & 2.517 \\
\hline & $\mathrm{Up}(\mathrm{m})$ & 2.708 & 2.588 & 2.826 & 4.058 & 8.058 \\
\hline & $3 \mathrm{D}(\mathrm{m})$ & 2.911 & 2.787 & 3.052 & 4.365 & 8.619 \\
\hline \multirow{4}{*}{$\begin{array}{l}\text { With A } \\
\text { Priori ISB } \\
\text { (6 days) }\end{array}$} & East (m) & 0.569 & 0.582 & 0.684 & 0.983 & 1.812 \\
\hline & North (m) & 0.914 & 0.874 & 0.966 & 1.344 & 2.596 \\
\hline & $\mathrm{Up}(\mathrm{m})$ & 2.702 & 2.597 & 2.884 & 4.227 & 8.430 \\
\hline & 3D (m) & 2.909 & 2.801 & 3.117 & 4.544 & 9.005 \\
\hline \multirow{4}{*}{$\begin{array}{l}\text { With A } \\
\text { Priori ISB } \\
\text { (7 days) }\end{array}$} & East (m) & 0.575 & 0.591 & 0.692 & 1.002 & 1.861 \\
\hline & North (m) & 0.911 & 0.873 & 0.966 & 1.353 & 2.635 \\
\hline & $\mathrm{Up}(\mathrm{m})$ & 2.698 & 2.604 & 2.907 & 4.316 & 8.700 \\
\hline & $3 \mathrm{D}(\mathrm{m})$ & 2.906 & 2.809 & 3.140 & 4.633 & 9.279 \\
\hline
\end{tabular}


Table 5. Improvement rates of positioning accuracy in (m) for the seven four-system SPP cases considering a priori ISB constraints over the one ignoring a priori ISB constraints under different elevation masks.

\begin{tabular}{|c|c|c|c|c|c|c|}
\hline \multirow{2}{*}{ Strategy } & \multirow{2}{*}{ Directions } & \multicolumn{5}{|c|}{ Elevation Mask Angles } \\
\hline & & $10^{\circ}$ & $20^{\circ}$ & $30^{\circ}$ & $40^{\circ}$ & $50^{\circ}$ \\
\hline \multirow{4}{*}{$\begin{array}{l}\text { With A } \\
\text { Priori ISB } \\
\text { (1 day) }\end{array}$} & East (\%) & 3 & 5 & 7 & 22 & 25 \\
\hline & North (\%) & 3 & 5 & 9 & 27 & 26 \\
\hline & $\mathrm{Up}(\%)$ & 4 & 5 & 9 & 24 & 23 \\
\hline & $3 \mathrm{D}(\%)$ & 4 & 5 & 9 & 24 & 23 \\
\hline \multirow{4}{*}{$\begin{array}{l}\text { With A } \\
\text { Priori ISB } \\
\text { (2 days) }\end{array}$} & East (\%) & 1 & 3 & 4 & 20 & 23 \\
\hline & North $(\%)$ & 3 & 5 & 8 & 26 & 25 \\
\hline & Up (\%) & 4 & 5 & 9 & 23 & 21 \\
\hline & $3 \mathrm{D}(\%)$ & 4 & 5 & 9 & 23 & 21 \\
\hline \multirow{4}{*}{$\begin{array}{l}\text { With A } \\
\text { Priori ISB } \\
\text { (3 days) }\end{array}$} & East (\%) & 0 & 1 & 2 & 18 & 22 \\
\hline & North $(\%)$ & 3 & 4 & 7 & 26 & 24 \\
\hline & $\mathrm{Up}(\%)$ & 4 & 5 & 8 & 21 & 19 \\
\hline & $3 \mathrm{D}(\%)$ & 4 & 5 & 8 & 22 & 19 \\
\hline \multirow{4}{*}{$\begin{array}{l}\text { With A } \\
\text { Priori ISB } \\
\text { (4 days) }\end{array}$} & East (\%) & -1 & -1 & 1 & 16 & 20 \\
\hline & North (\%) & 3 & 4 & 7 & 25 & 23 \\
\hline & Up (\%) & 4 & 4 & 7 & 20 & 17 \\
\hline & $3 \mathrm{D}(\%)$ & 3 & 4 & 6 & 20 & 17 \\
\hline \multirow{4}{*}{$\begin{array}{l}\text { With A } \\
\text { Priori ISB } \\
\text { (5 days) }\end{array}$} & East (\%) & -4 & -4 & -2 & 14 & 17 \\
\hline & North (\%) & 2 & 3 & 5 & 23 & 20 \\
\hline & $\mathrm{Up}(\%)$ & 3 & 4 & 5 & 17 & 13 \\
\hline & 3D (\%) & 3 & 3 & 4 & 18 & 14 \\
\hline \multirow{4}{*}{$\begin{array}{l}\text { With A } \\
\text { Priori ISB } \\
\text { (6 days) }\end{array}$} & East (\%) & -6 & -7 & -7 & 10 & 14 \\
\hline & North (\%) & 2 & 2 & 3 & 21 & 18 \\
\hline & Up (\%) & 4 & 3 & 3 & 14 & 9 \\
\hline & $3 \mathrm{D}(\%)$ & 3 & 3 & 2 & 14 & 10 \\
\hline \multirow{4}{*}{$\begin{array}{c}\text { With A } \\
\text { Priori ISB } \\
\text { (7 days) }\end{array}$} & East (\%) & -7 & -9 & -8 & 8 & 12 \\
\hline & North (\%) & 2 & 2 & 3 & 20 & 17 \\
\hline & Up (\%) & 4 & 3 & 2 & 12 & 6 \\
\hline & $3 \mathrm{D}(\%)$ & 3 & 3 & 2 & 13 & 7 \\
\hline
\end{tabular}

Table 6 provides the availability, satellite number, and position dilution of precision (PDOP) value of four-system integrated SPP with and without a priori ISB constraints under different elevation masks. The average satellite number and average PDOP value over all the available epochs (from all the employed stations and days in this section) are calculated. As to the availability, it is defined as the percentage of the epochs at which the position solutions can be acquired over the total epochs. For the four-system SPP ignoring a priori ISB constraints, the availability starts to decrease at an elevation mask of $40^{\circ}$ and is reduced to only $64.0 \%$ at an elevation mask of $50^{\circ}$. By contrast, the availability still remains at $100.0 \%$ for the four-system SPP considering a priori ISB constraints when the cutoff elevation is increased to $40^{\circ}$ and can be up to approximately $90.0 \%$ at an elevation mask of $50^{\circ}$. Under a cutoff elevation of $50^{\circ}$, for the four-system SPP without a priori ISB constraints, the average satellite number and PDOP value are 9.3 and 7.0, respectively, while the average satellite number decreases to 8.4 , and the average PDOP value increases to $8.2-8.3$ for the four-system SPP with a priori ISB constraints, indicating that many unsolvable epochs suffering from the extremely adverse observation conditions become solvable after introducing the a priori ISB constraints. 
Table 6. Availability, satellite number, and PDOP value of four-system integrated SPP with and without a priori ISB constraints under different elevation masks.

\begin{tabular}{ccccccc}
\hline \multirow{2}{*}{ Strategy } & \multirow{2}{*}{ Items } & \multicolumn{5}{c}{ Elevation Mask Angles } \\
\cline { 3 - 6 } & & $\mathbf{1 0}^{\circ}$ & $\mathbf{2 0}^{\circ}$ & $\mathbf{3 0}^{\circ}$ & $\mathbf{4 0}^{\circ}$ & $\mathbf{5 0}^{\circ}$ \\
\hline \multirow{2}{*}{ Without A } & Availability (\%) & 100.0 & 100.0 & 100.0 & 97.9 & 64.0 \\
Priori ISB & Num. of Sats. & 30.7 & 23.9 & 17.8 & 12.6 & 9.3 \\
& PDOP & 1.0 & 1.3 & 2.1 & 3.8 & 7.0 \\
\hline With A & Availability (\%) & 100.0 & 100.0 & 100.0 & 100.0 & $89.3-89.6$ \\
Priori ISB & Num. of Sats. & 30.7 & 23.9 & 17.8 & 12.5 & 8.4 \\
$(1-7$ days) & PDOP & 1.0 & 1.3 & 2.1 & 3.8 & $8.2-8.3$ \\
\hline
\end{tabular}

\subsection{ISB Estimates Derived from Low-Cost Receivers}

In order to investigate the ISB characteristics of low-cost receivers, a SPP experiment with the u-blox M8T receiver was conducted within the new campus of the Central South University in Changsha, China, on 31 October to 1 November 2021 (DOY 304 to 305 of 2021). Figure 12 presents the observation equipment for the SPP experiment. The u-blox M8T receiver with an active antenna with $3 \mathrm{~m}$ cable was connected with a laptop through the Universal Serial Bus (USB) socket to collect the GNSS data. The built-in USB interface can provide both power supply and high-speed data transfer. The observation equipment was set up on the roof of the Geoscience Building of the Central South University. To obtain the references for the SPP solutions based on the double-differenced RTK results, a MS352 receiver (manufactured by Guangzhou Hi-Target Satellite Navigation Technology Co., Ltd., Guangzhou, China) with a BY500 antenna (manufactured by Hunan BYNAV Technology Co., Ltd., Changsha, China) was set up as a base station, which was only several meters away from the rover station (u-blox M8T receiver). It is noted that the employed $\mathrm{u}$-blox M8T receiver only supports the GPS and GLONASS satellites but cannot track the Galileo and BDS (BDS-3/BDS-2) satellites. The SPP experiment lasted for approximately $12 \mathrm{~h}$ from 2:00 to 14:00 (GPS Time) for each day. The sampling interval was $1 \mathrm{~s}$.

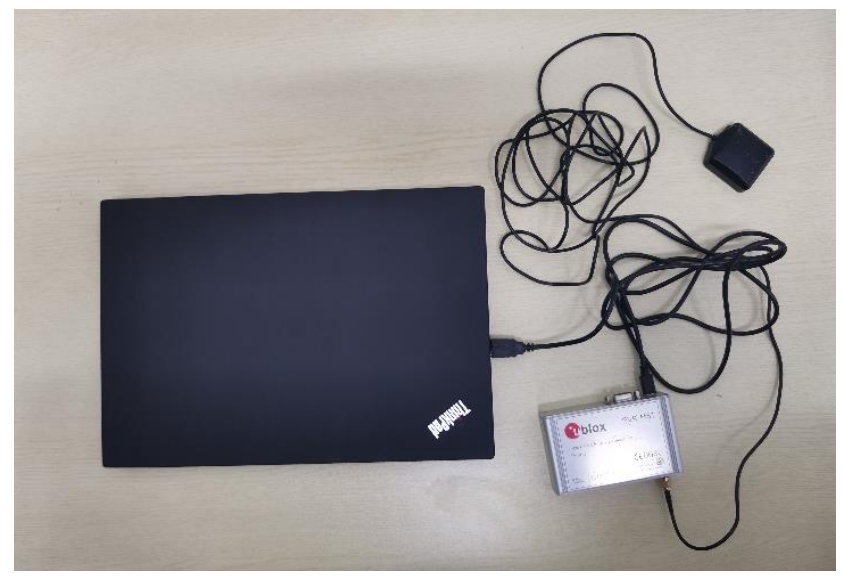

Figure 12. Observation equipment for the SPP experiment.

Figure 13 provides the epochwise ISB estimates between GLONASS and GPS derived from the dual-system integrated SPP solutions with the low-cost u-blox M8T receiver at an elevation mask angle of $10^{\circ}$ on DOY 304 and 305 of 2021. The varying range can be up to approximately $30 \mathrm{~ns}$ for the epochwise ISBs, with a STD statistic over the $12 \mathrm{~h}$ of 4.900 and $4.565 \mathrm{~ns}$ on the two days, respectively. The average value of epochwise ISBs over the $12 \mathrm{~h}$ is taken as the daily ISB. The prediction accuracy of daily ISB with a time span of prediction of a day is about $4 \mathrm{~ns}$. Both the short-term stability of epochwise ISB and the single-day prediction accuracy of daily ISB are worse than those obtained with the geodetic receivers (see Figures 5 and 9). 


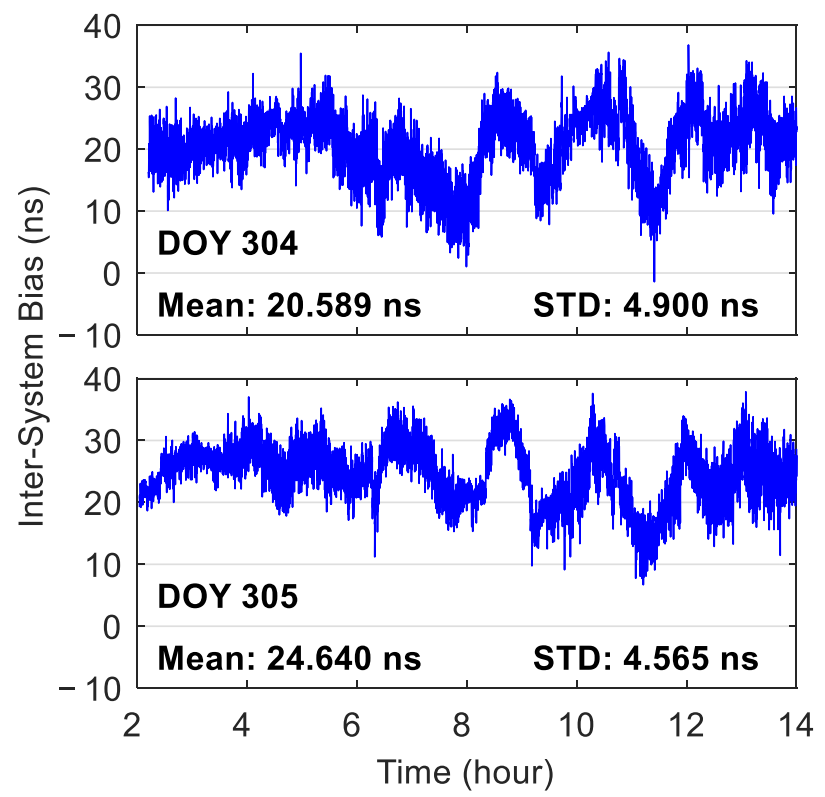

Figure 13. Epochwise ISB estimates between GLONASS and GPS derived from low-cost u-blox M8T receiver at an elevation mask angle of $10^{\circ}$ on DOY 304 and 305 of 2021.

To investigate the performance enhancement of a priori ISB constraints for the SPP solutions with the low-cost u-blox M8T receiver, the GPS/GLONASS integrated SPP processing with and without a priori ISB constraints based on the 12-h data sets on DOY 305 of 2021 under the cutoff elevations from $10^{\circ}$ to $50^{\circ}$ in steps of $10^{\circ}$ is carried out. The a priori ISBs are acquired by prediction with the daily ISB estimates of the previous day (DOY 304 of 2021). For the SPP solutions ignoring a priori ISBs, the availability decreases to $89.7 \%$ at an elevation mask of $40^{\circ}$ and is further reduced to only $18.6 \%$ at an elevation mask of $50^{\circ}$. After introducing the a priori ISB constraints, the corresponding availability increases to $92.9 \%$ and $28.5 \%$, respectively. As to the accuracy improvement coming with a priori ISB constraints, it is confined to several centimeters in terms of the 3D component under the cutoff elevations of $10^{\circ}$ and $20^{\circ}$ and reaches the optimal level at an elevation mask of $30^{\circ}$. The $3 \mathrm{D}$ accuracy improvement is less than $2 \mathrm{dm}$ when the cutoff elevations are further increased to $40^{\circ}$ and $50^{\circ}$, due to the inclusion of more position solutions at a lower accuracy level for the SPP processing with a priori ISB constraints. Figure 14 illustrates the SPP results under a cutoff elevation of $30^{\circ}$. The accuracy improvement is obvious in the up direction after taking the a priori ISB constraints into consideration, and the epochwise position errors usually vary within a range of 10,10, and $20 \mathrm{~m}$ in the east, north, and up directions, respectively. Compared with the SPP solutions without a priori ISB constraints, the positioning accuracy (i.e., RMS statistics of epochwise position errors) for those with a priori ISB constraints is improved by approximately 1.5 and $6.3 \mathrm{dm}(10 \%$ and $11 \%$ ) in the east and up directions, respectively, but slightly degrades by about $3 \mathrm{~cm}$ in the north direction. The limited performance enhancement that benefits from the a priori ISB constraints may be attributed to the combination of only two satellite systems and the worse ISB estimates with the low-cost receiver. 

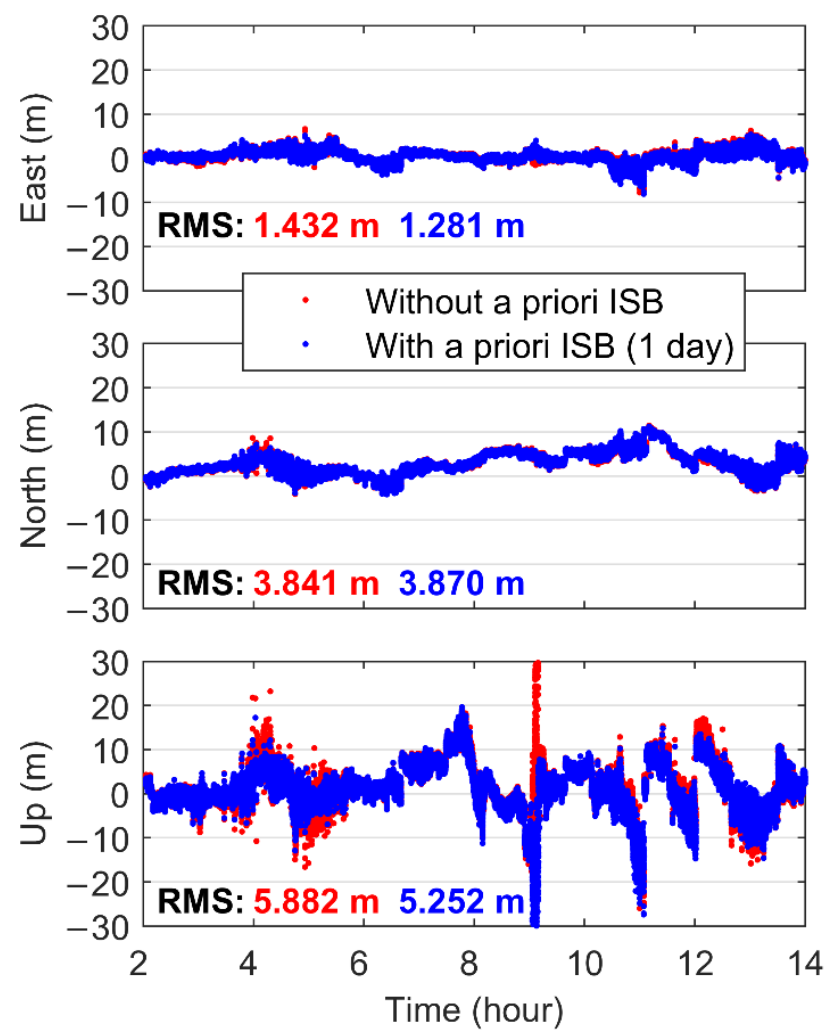

Figure 14. Epochwise positioning errors of GPS/GLONASS integrated SPP with and without a priori ISB constraints using the low-cost u-blox M8T receiver under a cutoff elevation of $30^{\circ}$ on DOY 305 of 2021.

\subsection{ISB Estimates Derived from Smartphones}

Smartphones with built-in low-cost GNSS chipsets and linearly polarized GNSS antenna have been widely applied to the SPP processing in recent years. The ISB estimates derived from the smartphones are characterized in this section. As shown in Figure 15, two Xiaomi Mi8 smartphones, which are identified by Xiaomi Mi8 (1) and Xiaomi Mi8 (2), are used to conduct the SPP experiment, and both of them can support GPS, GLONASS, Galileo, BDS-2, and BDS-3 satellites. The SPP experiment was carried out within the main campus of the Central South University in Changsha, China, on DOY 319 to 320 of 2020, and lasted for approximately $5 \mathrm{~h}$ and $20 \mathrm{~min}$ for each day, namely from 9:20 to 14:40 (GPS Time) for the first day and from 8:55 to 14:14 (GPS Time) for the second day. The two smartphones with a distance of several decimeters were set up on the roof of the Mining Building of the Central South University, and the multi-GNSS data were collected at a sampling interval of $1 \mathrm{~s}$. After the data collection with smartphones, a Trimble NetR9 receiver with a TRM57970.00 antenna was set up on the almost identical places to help determine the reference coordinates of the two smartphones using the double-differenced RTK approach. For the RTK processing, a base station with the same type of receiver and antenna was also set up on the roof of the Mining Building and was only several meters away from the smartphones. 


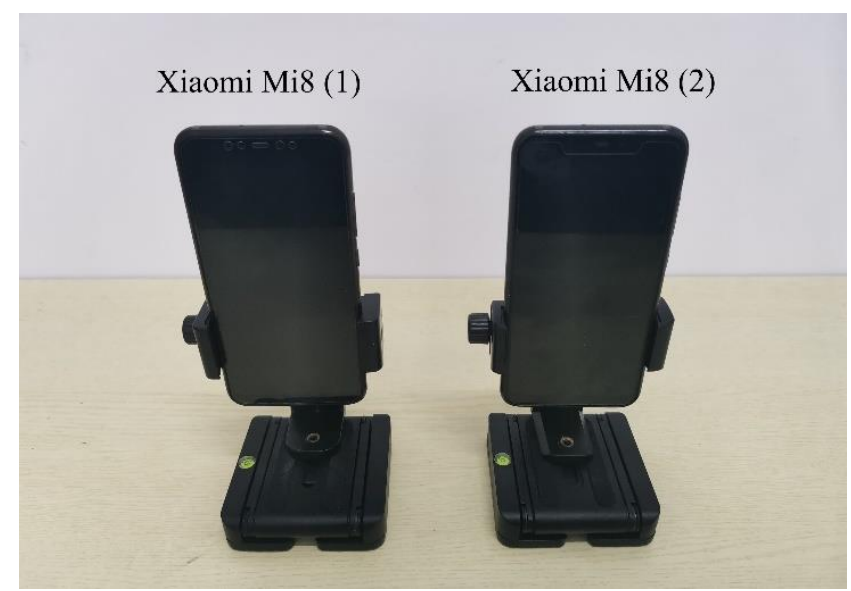

Figure 15. Two smartphones for the SPP experiment.

Figure 16 presents the epochwise ISB estimates for GLONASS, Galileo, BDS-2, and BDS-3 with respect to GPS derived from the four-system integrated SPP with the two Xiaomi Mi8 smartphones under a cutoff elevation of $10^{\circ}$ on DOY 319 and 320 of 2020. In conjunction with the ISB results obtained with the geodetic receiver and the low-cost u-blox M8T receiver (see Figures 2 and 13), the fluctuations are much more dramatic for those derived from the smartphones, which can be up to approximately $45 \mathrm{~ns}$ for the epochwise ISBs between Galileo and GPS, between BDS-2 and GPS, and between BDS-3 and GPS and approximately $120 \mathrm{~ns}$ for the epochwise ISBs between GLONASS and GPS, respectively. The epochwise ISB estimates at some epochs between BDS-3 and GPS on DOY 319 of 2020 for Xiaomi Mi8 (1) and on DOY 320 of 2020 for Xiaomi Mi8 (2) and between BDS-2 and GPS on DOY 319 of 2020 for Xiaomi Mi8 (2) have larger varying range, which can be attributed to the limited visible BDS-3 or BDS-2 satellites with a number of only two. The epochwise ISBs at partial epochs on DOY 320 of 2020 between BDS-3 and GPS for the two smartphones and between Galileo and GPS for Xiaomi Mi8 (1) are absent due to the availability of only a BDS-3 or Galileo satellite. The average value and STD statistic of epochwise ISBs over all the available epochs for each session for the two smartphones are listed in Table 7. The epochwise ISBs between GLONASS and GPS have the worst shortterm stability, with a STD statistic of 17.135-19.357 ns, while the corresponding statistics are 5.994-7.896, 6.670-7.966, and 6.768-12.185 ns for those between Galileo and GPS, between BDS-2 and GPS, and between BDS-3 and GPS, respectively. The average value of epochwise ISBs is taken as the daily ISB. Regarding the Xiaomi Mi8 (1) smartphone, the single-day prediction accuracy of daily ISB is $6.643,0.811,3.389$, and 3.732 ns for GLONASS, Galileo, BDS-2, and BDS-3 with respect to GPS, respectively, while the corresponding prediction accuracy is improved to 2.090,1.357, 1.435, and $0.814 \mathrm{~ns}$ for the four groups of daily ISBs for the Xiaomi Mi8 (2) smartphone, respectively, which is still worse than that with the geodetic devices (see Figure 9). For the two smartphones of the same brand, the daily ISBs are roughly consistent, and the differences are 1.597-2.956, 0.220-0.326, 3.413-5.367, and 0.230-4.316 ns for GLONASS, Galileo, BDS-2, and BDS-3 with respect to GPS, respectively. 


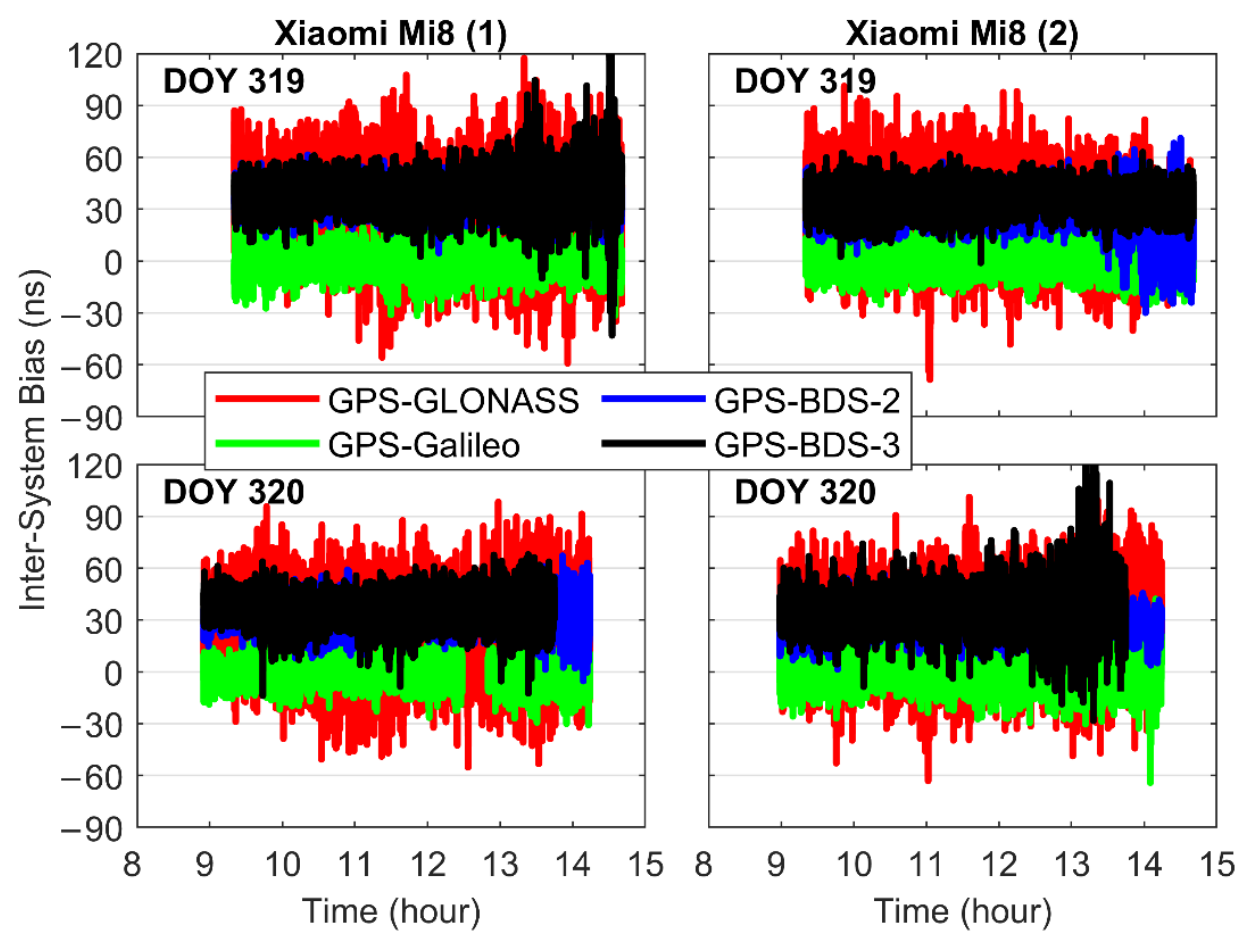

Figure 16. Epochwise ISB estimates for two smartphones on DOY 319 and 320 of 2020.

Table 7. Average value and STD of epochwise ISBs for two smartphones.

\begin{tabular}{|c|c|c|c|c|c|c|}
\hline \multirow[b]{2}{*}{ Devices } & \multirow[b]{2}{*}{ DOY } & \multirow[b]{2}{*}{ Items } & \multicolumn{4}{|c|}{ Statistics of Epochwise ISBs (ns) } \\
\hline & & & $\begin{array}{c}\text { GPS- } \\
\text { GLONASS }\end{array}$ & $\begin{array}{c}\text { GPS- } \\
\text { Galileo }\end{array}$ & GPS-BDS-2 & GPS-BDS-3 \\
\hline \multirow{4}{*}{$\begin{array}{l}\text { Xiaomi } \\
\text { Mi8 (1) }\end{array}$} & \multirow{2}{*}{319} & Average & 30.285 & 0.064 & 35.957 & 39.839 \\
\hline & & STD & 19.357 & 7.038 & 6.754 & 10.697 \\
\hline & \multirow{2}{*}{320} & Average & 23.642 & -0.747 & 32.568 & 36.107 \\
\hline & & STD & 17.949 & 5.994 & 6.670 & 7.897 \\
\hline \multirow{4}{*}{$\begin{array}{l}\text { Xiaomi } \\
\text { Mi8 (2) }\end{array}$} & \multirow{2}{*}{319} & Average & 27.329 & 0.390 & 30.590 & 35.523 \\
\hline & & STD & 17.135 & 6.365 & 7.966 & 6.768 \\
\hline & \multirow{2}{*}{320} & Average & 25.239 & -0.967 & 29.155 & 36.337 \\
\hline & & STD & 18.599 & 7.896 & 7.039 & 12.185 \\
\hline
\end{tabular}

To investigate the enhanced performance for the SPP solutions considering a priori ISB constraints with the use of smartphones, the smartphone-based four-system integrated SPP processing with and without a priori ISB constraints is compared. The daily ISBs on DOY 319 of 2020 are introduced into the SPP processing on DOY 320 of 2020 as a priori constraints. For completeness, in addition to the SPP processing under open sky with an elevation mask of $10^{\circ}$, the cutoff elevations are increased to $20^{\circ}, 30^{\circ}, 40^{\circ}$, and $50^{\circ}$ to perform the SPP processing in the constrained visibility environments. Figure 17 illustrates the epochwise positioning errors of four-system integrated SPP for two Xiaomi Mi8 smartphones with and without a priori ISB constraints under a cutoff elevation of $40^{\circ}$ on DOY 320 of 2020 . When ignoring the a priori ISBs, the epochwise position errors vary within 20,20, and $40 \mathrm{~m}$ for most of the time in the east, north, and up directions, respectively, but can exceed $60 \mathrm{~m}$ after 14:00 (GPS Time) in all the three directions, except for the north direction for Xiaomi Mi8 (2). After considering the a priori ISB constraints, the epochwise position errors are reduced in all the three directions, especially for those after 14:00 (GPS Time) with an accuracy improvement of tens of meters. 

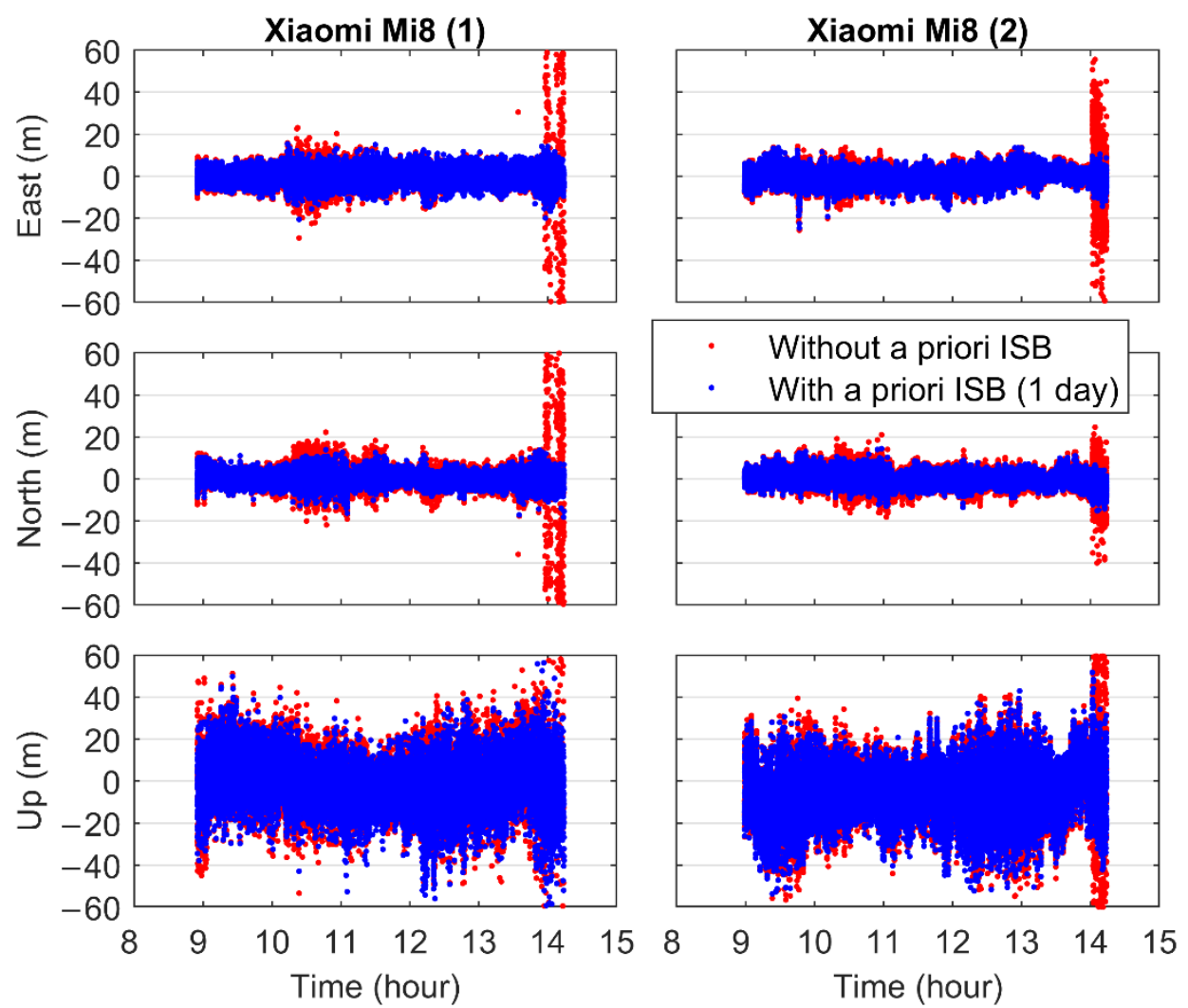

Figure 17. Epochwise positioning errors of four-system integrated SPP for two smartphones with and without a priori ISB constraints under a cutoff elevation of $40^{\circ}$ on DOY 320 of 2020.

For further analysis, Table 8 provides the positioning accuracy (i.e., RMS statistics of epochwise position errors) in (m) of four-system integrated SPP for two smartphones with and without a priori ISB constraints under different elevation masks. For the smartphonebased four-system integrated SPP considering a priori ISB constraints, the positioning accuracy can be about $2.5 \mathrm{~m}$ in the east and north directions, and about 5-7 $\mathrm{m}$ in the up direction, respectively, when the cutoff elevations are lower than or equal to $20^{\circ}$. The positioning accuracy degrades with the increasing elevation masks, and can be approximately $5-6,4-5$ and $23.5-24.5 \mathrm{~m}$ at an elevation mask of $50^{\circ}$ in the three directions, respectively. Compared with the SPP solutions without a priori ISB constraints, the positioning accuracy for those with a priori ISB constraints can be improved, and the corresponding improvement rates are listed in Table 9. Different from the results of improvement rates with the geodetic receivers (see Table 5), the accuracy improvement coming with a priori ISB constraints is also significant for the smartphone-based SPP applications when the cutoff elevations are no more than $30^{\circ}$. The accuracy improvement is the most obvious at an elevation mask of $50^{\circ}$, which can be $42 \%, 45 \%, 7 \%$, and $13 \%$ and $34 \%, 39 \%, 13 \%$, and $16 \%$ for Xiaomi Mi8 (1) and Xiaomi Mi8 (2) in the east, north, up, and 3D directions, respectively. 
Table 8. Positioning accuracy in ( $\mathrm{m}$ ) of four-system integrated SPP for two smartphones with and without a priori ISB constraints under different elevation masks.

\begin{tabular}{|c|c|c|c|c|c|c|c|}
\hline \multirow{2}{*}{ Devices } & \multirow{2}{*}{ Strategy } & \multirow{2}{*}{ Directions } & \multicolumn{5}{|c|}{ Elevation Mask Angles } \\
\hline & & & $10^{\circ}$ & $20^{\circ}$ & $30^{\circ}$ & $40^{\circ}$ & $50^{\circ}$ \\
\hline \multirow{8}{*}{$\begin{array}{l}\text { Xiaomi } \\
\text { Mi8 (1) }\end{array}$} & \multirow{4}{*}{$\begin{array}{l}\text { Without } \\
\text { A Priori } \\
\text { ISB }\end{array}$} & East (m) & 2.528 & 2.673 & 2.998 & 3.862 & 9.073 \\
\hline & & North (m) & 2.632 & 2.879 & 3.236 & 3.883 & 8.850 \\
\hline & & $\mathrm{Up}(\mathrm{m})$ & 6.044 & 8.064 & 10.264 & 12.650 & 25.571 \\
\hline & & $3 \mathrm{D}(\mathrm{m})$ & 7.060 & 8.970 & 11.172 & 13.784 & 28.540 \\
\hline & \multirow{4}{*}{$\begin{array}{c}\text { With A } \\
\text { Priori } \\
\text { ISB (1 } \\
\text { day) }\end{array}$} & East (m) & 2.437 & 2.586 & 2.886 & 3.454 & 5.237 \\
\hline & & North (m) & 2.348 & 2.455 & 2.650 & 2.903 & 4.908 \\
\hline & & $\mathrm{Up}(\mathrm{m})$ & 5.018 & 6.892 & 9.399 & 11.971 & 23.724 \\
\hline & & $3 \mathrm{D}(\mathrm{m})$ & 6.052 & 7.760 & 10.183 & 12.793 & 24.786 \\
\hline \multirow{8}{*}{$\begin{array}{l}\text { Xiaomi } \\
\text { Mi8 (2) }\end{array}$} & \multirow{4}{*}{$\begin{array}{l}\text { Without } \\
\text { A Priori } \\
\text { ISB }\end{array}$} & East (m) & 2.614 & 2.791 & 3.120 & 4.074 & 8.679 \\
\hline & & North (m) & 2.790 & 2.961 & 3.104 & 3.799 & 6.423 \\
\hline & & $\mathrm{Up}(\mathrm{m})$ & 6.866 & 8.328 & 10.369 & 14.994 & 28.309 \\
\hline & & $3 \mathrm{D}(\mathrm{m})$ & 7.859 & 9.269 & 11.264 & 15.995 & 30.299 \\
\hline & With A & East (m) & 2.477 & 2.645 & 2.855 & 3.579 & 5.763 \\
\hline & Priori & North (m) & 2.499 & 2.565 & 2.599 & 3.019 & 3.925 \\
\hline & ISB (1 & $\mathrm{Up}(\mathrm{m})$ & 5.858 & 7.237 & 9.403 & 13.721 & 24.587 \\
\hline & day) & $3 \mathrm{D}(\mathrm{m})$ & 6.834 & 8.121 & 10.165 & 14.498 & 25.556 \\
\hline
\end{tabular}

Table 9. Improvement rates of positioning accuracy in $(\mathrm{m})$ for the smartphone-based four-system integrated SPP considering a priori ISB constraints over the one ignoring a priori ISB constraints under different elevation masks.

\begin{tabular}{lcccccc}
\hline \multirow{2}{*}{ Devices } & Directions & \multicolumn{5}{c}{ Elevation Mask Angles } \\
\cline { 3 - 6 } & & $\mathbf{1 0}^{\circ}$ & $\mathbf{2 0}^{\circ}$ & $\mathbf{3 0}^{\circ}$ & $\mathbf{4 0}$ & $\mathbf{5 0}^{\circ}$ \\
\hline \multirow{3}{*}{ Xiaomi } & East (\%) & 4 & 3 & 4 & 11 & 42 \\
Mi8 (1) & North (\%) & 11 & 15 & 18 & 25 & 45 \\
& Up (\%) & 17 & 15 & 8 & 5 & 7 \\
& 3D (\%) & 14 & 13 & 9 & 7 & 13 \\
\hline \multirow{2}{*}{ Xiaomi } & East (\%) & 5 & 5 & 8 & 12 & 34 \\
Mi8 (2) & North (\%) & 10 & 13 & 16 & 21 & 39 \\
& Up (\%) & 15 & 13 & 9 & 8 & 13 \\
& 3D (\%) & 13 & 12 & 10 & 9 & 16 \\
\hline
\end{tabular}

Table 10 provides the availability, average satellite number, and average PDOP value of four-system integrated SPP for two smartphones with and without a priori ISB constraints under different elevation masks. Similar to the availability results with the geodetic receivers (see Table 6), the availability for the four-system integrated SPP with smartphones ignoring a priori ISBs also starts to slightly decrease at an elevation mask of $40^{\circ}$. Under a cutoff elevation of $50^{\circ}$, the corresponding availability declines to only $62.7 \%$ and $69.9 \%$ for Xiaomi Mi8 (1) and Xiaomi Mi8 (2), respectively. After introducing the a priori ISB constraints, the availability still keeps $100.0 \%$ at an elevation mask of $40^{\circ}$ and is improved to $82.9 \%$ and $93.0 \%$ at an elevation mask of $50^{\circ}$ for the two smartphones, respectively. In view that many unsolvable epochs become solvable after considering the a priori ISB constraints under a cutoff elevation of $50^{\circ}$, the average satellite number is reduced from 8.7 and 9.5 to 8.2 and 8.8 for the two smartphones, respectively, while the corresponding average PDOP value is increased from 8.4 and 7.2 to 9.0 and 7.4, respectively. The average satellite number for the smartphone-based four-system integrated SPP is 20.0 and 22.4 for the two Xiaomi Mi8 smartphones at an elevation mask of $10^{\circ}$, respectively, which is significantly less than that derived from the geodetic-type receivers with a statistic of 30.7 (see Table 6), indicating that the capability of tracking GNSS signals needs to be enhanced for the smartphones. 
Table 10. Availability, satellite number, and PDOP value of four-system integrated SPP for two smartphones with and without a priori ISB constraints under different elevation masks.

\begin{tabular}{|c|c|c|c|c|c|c|c|}
\hline \multirow{2}{*}{ Devices } & \multirow{2}{*}{ Strategy } & \multirow{2}{*}{ Items } & \multicolumn{5}{|c|}{ Elevation Mask Angles } \\
\hline & & & $10^{\circ}$ & $20^{\circ}$ & $30^{\circ}$ & $40^{\circ}$ & $50^{\circ}$ \\
\hline \multirow{6}{*}{$\begin{array}{l}\text { Xiaomi } \\
\text { Mi8 (1) }\end{array}$} & \multirow{3}{*}{$\begin{array}{l}\text { Without A } \\
\text { Priori ISB }\end{array}$} & Availability (\%) & 100.0 & 100.0 & 100.0 & 95.7 & 62.7 \\
\hline & & Num. of Sats. & 20.0 & 17.8 & 14.8 & 11.8 & 8.7 \\
\hline & & PDOP & 1.3 & 1.7 & 2.5 & 3.9 & 8.4 \\
\hline & \multirow{3}{*}{$\begin{array}{c}\text { With A } \\
\text { Priori ISB (1 } \\
\text { day) }\end{array}$} & Availability (\%) & 100.0 & 100.0 & 100.0 & 100.0 & 82.9 \\
\hline & & Num. of Sats. & 20.0 & 17.8 & 14.8 & 11.5 & 8.2 \\
\hline & & PDOP & 1.3 & 1.7 & 2.5 & 4.0 & 9.0 \\
\hline \multirow{6}{*}{$\begin{array}{l}\text { Xiaomi } \\
\text { Mi8 (2) }\end{array}$} & \multirow{3}{*}{$\begin{array}{l}\text { Without A } \\
\text { Priori ISB }\end{array}$} & Availability (\%) & 100.0 & 100.0 & 100.0 & 98.3 & 69.9 \\
\hline & & Num. of Sats. & 22.4 & 20.1 & 16.6 & 13.0 & 9.5 \\
\hline & & PDOP & 1.2 & 1.5 & 2.3 & 3.7 & 7.2 \\
\hline & \multirow{3}{*}{$\begin{array}{c}\text { With A } \\
\text { Priori ISB (1 } \\
\text { day) }\end{array}$} & Availability (\%) & 100.0 & 100.0 & 100.0 & 100.0 & 93.0 \\
\hline & & Num. of Sats. & 22.4 & 20.1 & 16.6 & 12.9 & 8.8 \\
\hline & & PDOP & 1.2 & 1.5 & 2.3 & 3.7 & 7.4 \\
\hline
\end{tabular}

\section{Discussion}

The multisystem integration is expected to ensure the positioning performance in constrained visibility environments. However, the benefits from multisystem combination for positioning and navigation are limited under extremely harsh environments due to the distinct time scales and receiver-specific hardware delays among different GNSSs. For example, the position solutions are unsolvable if the visible satellites only include a GPS satellite, a GLONASS satellite, a Galileo satellite, a BDS-2 satellite, and a BDS-3 satellite, as the additional ISB parameters need to be simultaneously estimated. The characteristic analysis indicates that the daily ISBs have a good long-term stability; thus, the predicted high-accuracy ISBs (obtained in advance) can be used as a priori constraints to improve the benefits from multisystem combination for real-time positioning and navigation under extremely harsh environments. The four-system integrated SPP considering a priori ISB constraints with a prediction period of a day can provide a positioning accuracy better than 1.6 and $3.8 \mathrm{~m}$ and 2.9 and $7.2 \mathrm{~m}$ in the horizontal and vertical directions at an availability of approximately $100.0 \%$ and $90.0 \%$ under the cutoff elevations of $40^{\circ}$ and $50^{\circ}$, respectively, which is of great significance for the satellite navigation and low-accuracy positioning users.

\section{Conclusions}

With the rapid development of GNSSs, especially for BDS (BDS-3/BDS-2) and Galileo, the multisystem combination has been an emerging trend in recent years. The SPP technology, which is the open position service of GNSSs and is widely used in satellite navigation and low-accuracy positioning, can also benefit from the multi-GNSS integration. The compatibility among different GNSSs is a key issue in the multisystem integrated data processing. To solve this issue, the additional ISB parameters should be introduced into the observation model. In this study, we carefully characterize the ISB estimates for GLONASS, Galileo, BDS-2, and BDS-3 with respect to GPS in the four-system integrated SPP, and the performance enhancement of predicted ISBs as a priori constraints for multisystem SPP position solutions with a prediction period from a day to a week under a cutoff elevation angle from $10^{\circ}$ to $50^{\circ}$ (to simply simulate the harsh observation environments by increasing the elevation masks) is rigorously evaluated. The data sets from 120 globally distributed MGEX stations (covering seven different receiver types from three manufacturers) spanning a month from DOY 41 to 70 of 2020 are employed.

The results indicate that the epochwise ISB estimates are relatively stable with a varying range of approximately $10 \mathrm{~ns}$, and those of BDS-3 and BDS-2 show obvious differences by several nanoseconds. The daily ISBs do not present obvious fluctuations when the receiver firmware versions are changed, but the step changes can be observed 
for the daily ISBs when encountering the replacement of receiver types. The short-term stability of epochwise ISBs for GLONASS, Galileo, BDS-2, and BDS-3 with respect to GPS can be $2.335,1.262,1.741$, and $1.532 \mathrm{~ns}$, respectively, whereas the corresponding long-term stability for daily ISBs can be $1.258,1.288,2.713$, and $2.566 \mathrm{~ns}$, respectively. The effects of receiver types on the short-term and long-term stability of ISBs are not significant. The daily ISBs are roughly consistent for the stations equipped with the same type of receivers. The numerical values range from 20 to $45 \mathrm{~ns}$ for the daily ISBs between GLONASS and GPS, from 30 to $70 \mathrm{~ns}$ for the daily ISBs between BDS-2 and GPS, and from 25 to $65 \mathrm{~ns}$ for the daily ISBs between BDS-3 and GPS, respectively, while the numerical values of daily ISBs between Galileo and GPS range from -13 to $-7 \mathrm{~ns}$ for the stations with the TRIMBLE ALLOY receiver and from -5 to $3 \mathrm{~ns}$ for the stations with the other six types of receivers, respectively.

The single-day prediction residuals of daily ISBs (within the same group) for the stations with various receiver types are comparable to each other. The single-day prediction accuracy of daily ISBs for GLONASS, Galileo, BDS-2, and BDS-3 with respect to GPS can be $1.055,0.640,1.242$, and $0.849 \mathrm{~ns}$, respectively. The prediction accuracy of daily ISBs degrades with the increasing time span of prediction and a prediction accuracy of 1.767, $1.954,2.982$, and $2.580 \mathrm{~ns}$ can still be achieved for the four groups of daily ISBs when the time span of prediction is increased to seven days, respectively. The correction rates of predicted daily ISBs between Galileo and GPS are only $78.0 \%$ even when the time span of prediction is set to a day and decrease to $32.8 \%$ with a time span of prediction of a week, whereas the corresponding correction rates for the other three groups of daily ISBs keep over $93.0 \%$ with the increasing time span of ISB prediction.

The accuracy improvements that benefit from the a priori ISB constraints are marginal (less than $10 \%$ ) when the cutoff elevations are lower than or equal to $30^{\circ}$. The accuracy improvements coming with the a priori ISB constraints become significant when the elevation masks are further increased to $40^{\circ}$ and $50^{\circ}$. The accuracy improvements after introducing the a priori ISB constraints can be $22 \%, 27 \%, 24 \%$, and $24 \%$ and $25 \%, 26 \%, 23 \%$, and $23 \%$ at an elevation mask of $40^{\circ}$ and $50^{\circ}$ with a time span of ISB prediction of a day in the east, north, up, and 3D directions, respectively. Under a cutoff elevation of $40^{\circ}$ and $50^{\circ}$, the improvement rates decrease with the increasing time span of ISB prediction, and the corresponding accuracy improvements attributed to the a priori ISB constraints with a time span of ISB prediction of seven days can still be $8 \%, 20 \%, 12 \%$, and $13 \%$ and $12 \%$, $17 \%, 6 \%$, and $7 \%$ in the four directions, respectively. The availability starts to decrease at an elevation mask of $40^{\circ}$ and is reduced to only $64.0 \%$ at an elevation mask of $50^{\circ}$ for the four-system SPP ignoring a priori ISB constraints (traditional four-system SPP). By contrast, the availability still keeps $100.0 \%$ when the cutoff elevation is increased to $40^{\circ}$ and can be up to approximately $90.0 \%$ at an elevation mask of $50^{\circ}$ for the four-system SPP considering a priori ISB constraints.

In addition, we also characterize the ISB estimates derived from the low-cost $\mathrm{u}$-blox M8T receiver and two Xiaomi Mi8 smartphones and also investigate the performance enhancement of a priori ISB constraints for the multisystem SPP solutions. Although both the short-term stability of epochwise ISBs and the single-day prediction accuracy of daily ISBs with these devices are worse than those with the geodetic-type receivers, the position accuracy as well as the availability of the multisystem integrated SPP can be improved after introducing the a priori ISB constraints, especially for the SPP results with the smartphones. Usually, the receiver hardware delay is considered to change with the temperatures. However, the epochwise ISBs obtained with the u-blox M8T receiver and the Xiaomi Mi8 smartphone do not show obvious fluctuations in the first half an hour (with increased temperatures), which may be attributed to the worse ISB estimates with the low-cost SPP receivers.

Author Contributions: Conceptualization, L.P. and W.Y.; methodology, L.P.; software, L.P.; validation, L.P.; formal analysis, L.P.; investigation, L.P.; resources, L.P.; data curation, L.P.; writing—original draft preparation, L.P.; writing—review and editing, Z.Z., W.Y. and W.D.; visualization, L.P.; supervision, 
L.P.; project administration, L.P.; funding acquisition, L.P. All authors have read and agreed to the published version of the manuscript.

Funding: This research was funded by the National Natural Science Foundation of China (Grant No. 41904030), Natural Science Foundation of Hunan Province, China (Grant No. 2020JJ5706), State Key Laboratory of Geo-Information Engineering (Grant No. SKLGIE2019-Z-1-1), Science and Technology Project of Department of Natural Resources of Hunan Province (Grant No. 2021-24), and Guangxi Key Laboratory of Spatial Information and Geomatics (Grant No. 19-050-11-09).

Institutional Review Board Statement: Not applicable.

Informed Consent Statement: Not applicable.

Data Availability Statement: Publicly available data sets were analyzed in this study. These data can be found from MGEX.

Acknowledgments: The contribution of data from MGEX is appreciated.

Conflicts of Interest: The authors declare no conflict of interest.

\section{References}

1. Pan, L.; Zhang, X.; Liu, J.; Li, X.; Li, X. Performance Evaluation of Single-frequency Precise Point Positioning with GPS, GLONASS, BeiDou and Galileo. J. Navig. 2017, 70, 465-482. [CrossRef]

2. Odijk, D.; Teunissen, P.J.G. Characterization of between-receiver GPS-Galileo inter-system biases and their effect on mixed ambiguity resolution. GPS Solut. 2013, 17, 521-533. [CrossRef]

3. Paziewski, J.; Wielgosz, P. Accounting for Galileo-GPS inter-system biases in precise satellite positioning. J. Geod. 2015, 89, 81-93. [CrossRef]

4. Tian, Y.; Sui, L.; Xiao, G.; Zhao, D.; Chai, H.; Liu, C. Estimating inter-system biases for tightly combined Galileo/BDS/GPS RTK. Adv. Space Res. 2020, 65, 572-585. [CrossRef]

5. Mi, X.; Zhang, B.; Yuan, Y. Multi-GNSS inter-system biases: Estimability analysis and impact on RTK positioning. GPS Solut. 2019, 23, 81. [CrossRef]

6. Liu, X.; Jiang, W.; Chen, H.; Zhao, W.; Huo, L.; Huang, L.; Chen, Q. An analysis of inter-system biases in BDS/GPS precise point positioning. GPS Solut. 2019, 23, 116. [CrossRef]

7. Hong, J.; Tu, R.; Gao, Y.; Zhang, R.; Fan, L.; Zhang, P.; Liu, J. Characteristics of inter-system biases in Multi-GNSS with precise point positioning. Adv. Space Res. 2019, 63, 3777-3794. [CrossRef]

8. Zhang, F.; Liu, C.; Xiao, G.; Zhang, X.; Feng, X. Estimating and Analyzing Long-Term Multi-GNSS Inter-System Bias Based on Uncombined PPP. Sensors 2020, 20, 1499. [CrossRef] [PubMed]

9. Zhou, F.; Dong, D.; Li, P.; Li, X.; Schuh, H. Influence of stochastic modeling for inter-system biases on multi-GNSS undifferenced and uncombined precise point positioning. GPS Solut. 2019, 23, 59. [CrossRef]

10. Cao, X.; Shen, F.; Zhang, S.; Li, J. Time delay bias between the second and third generation of BeiDou Navigation Satellite System and its effect on precise point positioning. Measurement 2021, 168, 108346. [CrossRef]

11. Zhao, W.; Chen, H.; Gao, Y.; Jiang, W.; Liu, X. Evaluation of Inter-System Bias between BDS-2 and BDS-3 Satellites and Its Impact on Precise Point Positioning. Remote Sens. 2020, 12, 2185. [CrossRef]

12. Jiang, N.; Xu, Y.; Xu, T.; Xu, G.; Sun, Z.; Schuh, H. GPS/BDS short-term ISB modelling and prediction. GPS Solut. 2017, 21, 163-175. [CrossRef]

13. Geng, J.; Li, X.; Zhao, Q.; Li, G. Inter-system PPP ambiguity resolution between GPS and BeiDou for rapid initialization. J. Geod. 2019, 93, 383-398. [CrossRef]

14. Gioia, C.; Borio, D. A statistical characterization of the Galileo-to-GPS inter-system bias. J. Geod. 2016, 90, 1279-1291. [CrossRef]

15. Zeng, A.; Yang, Y.; Ming, F.; Jing, Y. BDS-GPS inter-system bias of code observation and its preliminary analysis. GPS Solut. 2017, 21, 1573-1581. [CrossRef]

16. Torre, A.D.; Caporali, A. An analysis of intersystem biases for multi-GNSS positioning. GPS Solut. 2015, 19, 297-307. [CrossRef] 